\title{
Working
}

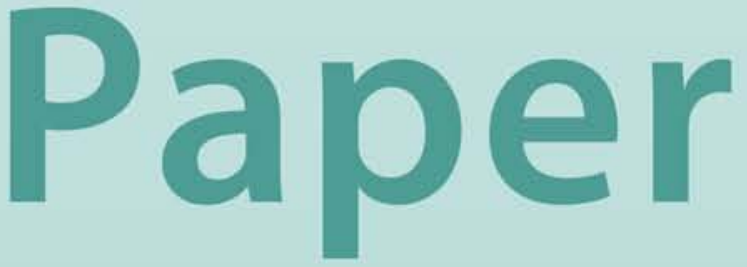


Investment-Specific Technology Shocks and International Business Cycles:

An Empirical Assessment

Federico S. Mandelman, Pau Rabanal, Juan F. Rubio-Ramírez, and Diego Vilán 


\title{
IMF Working Paper
}

\author{
Research Department
}

\section{Investment-Specific Technology Shocks and International Business Cycles: An Empirical Assessment ${ }^{1}$}

\author{
Prepared by Federico S. Mandelman, Pau Rabanal, \\ Juan F. Rubio-Ramírez, and Diego Vilán \\ Authorized for distribution by Gian Maria Milesi-Ferretti
}

September 2010

\begin{abstract}
This Working Paper should not be reported as representing the views of the IMF.

The views expressed in this Working Paper are those of the author(s) and do not necessarily represent those of the IMF or IMF policy. Working Papers describe research in progress by the author(s) and are published to elicit comments and to further debate.

In this paper, we first introduce investment-specific technology (IST) shocks to an otherwise standard international real business cycle model and show that a thoughtful calibration of them along the lines of Raffo (2009) successfully addresses the "quantity", "international comovement", "Backus-Smith", and "price" puzzles. Second, we use OECD data for the relative price of investment to build and estimate these IST processes across the U.S and a "rest of the world" aggregate, showing that they are cointegrated and well represented by a vector error correction model (VECM). Finally, we demonstrate that when we fit such estimated IST processes in the model instead of the calibrated ones, the shocks are actually not as powerful to explain any of the four montioned puzzles.

JEL Classification Numbers: $\quad$ E32, F32, F33, F41

Keywords: International Business Cycles, Cointegration, Investment-Specific Technology Shocks Author’s E-Mail Address: $\quad$ Federico.mandelman@atl.frb.org; prabanal@imf.org; juan.rubioramirez@duke.edu; vilan@usc.edu

\footnotetext{
${ }^{1}$ We thank Martín Uribe, Jesper Lindé an anonymous referee, and seminar participants at SCIEA at the Federal Reserve Bank of Dallas for very helpful comments and suggestions. Beyond the usual disclaimer, we must note that any views expressed herein are those of the authors and not necessarily those of the Federal Reserve Bank of Atlanta, the Federal Reserve System, FEDEA, or the International Monetary Fund. Finally, we also thank the NSF for financial support. Federico Mandelman is an economist at the Federal Reserve Bank of Atlanta, Research Department, Pau Rabanal is an economist in the Research Department of the IMF, Juan Rubio-Ramirez is an associate professor at Duke University, and Diego Vilán is a graduate student at the University of Southern California.
} 


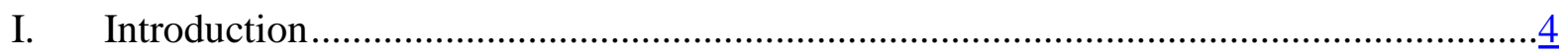

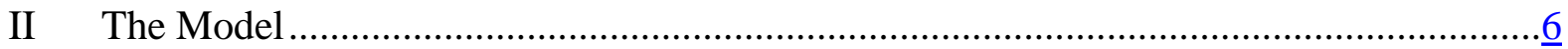

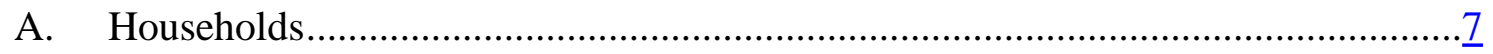

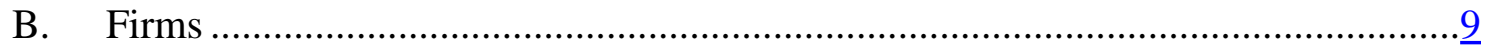

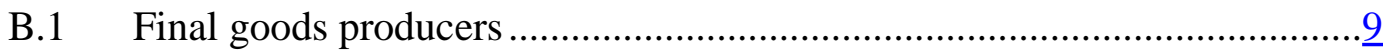

B.2 Intermediate goods producers .......................................................

B.3 The VECMs for IST and TFP Shocks .............................................10

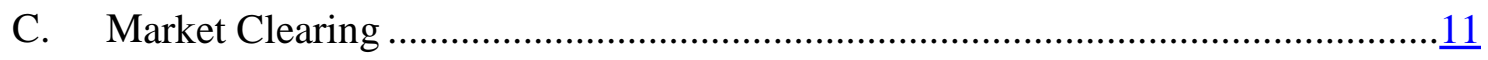

D. Equilibrium and Equilibrium Conditions.......................................................11

D.1 Equilibrium conditions.................................................................... 11

E. Balanced Growth and the Restriction on the Cointegrating Vector ......................14

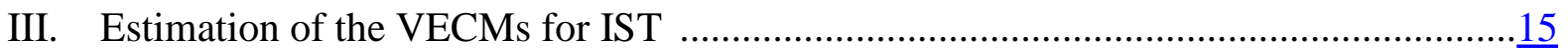

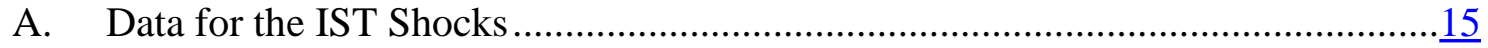

B. Integration and Cointegration Properties of the IST Shocks ..............................17

C. The Estimated VECM for IST Shocks............................................................19

D. The Estimated VECM for TFP Shocks.......................................................19

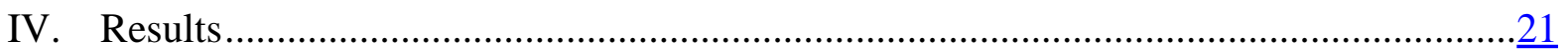

A. Model Parameterization ............................................................................... 21

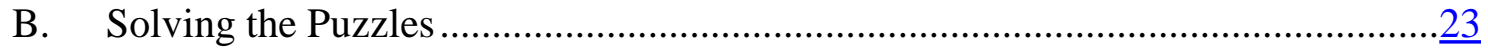

C. IRBC with the Estimated IST Shocks.........................................................

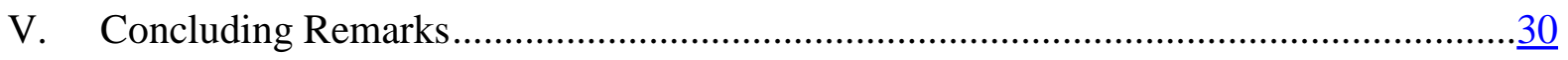

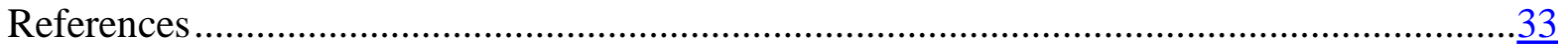

Appendix I

A. Normalized Equilibrium Conditions ........................................................

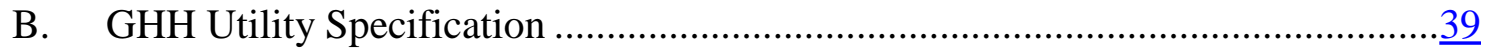

C. Estimation for the VECMs for TFP Shocks .................................................. 40

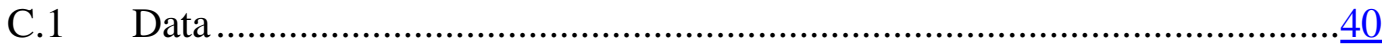

C.2 Integration and Cointegration Properties ............................................ 41

C.3 The VECM Model ....................................................................

Text Tables

1. Unit Root Tests for IST Shocks .....................................................................

2. Cointegration Statistics II: Johansen's Test......................................................18 


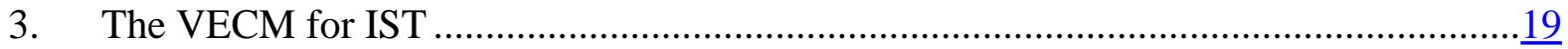

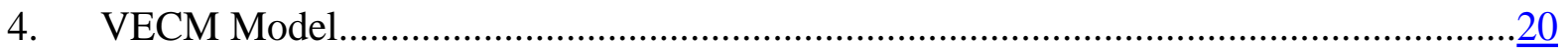

5a. Stationary Model Results .....................................................................................26

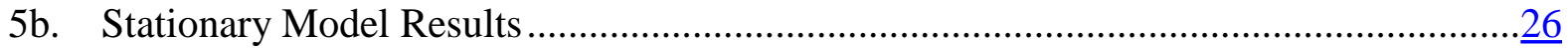

5c. Stationary Model Results ..................................................................................... 26

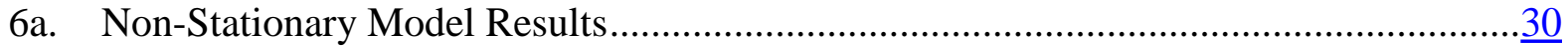

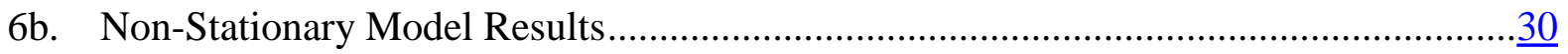

6c. Non-Stationary Model Results................................................................................

Appendix Tables

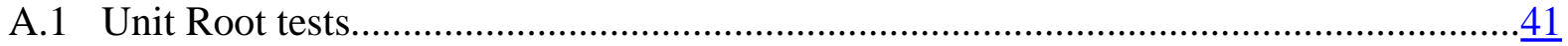

A.2 Cointegration Statistics II: Johansen's tests............................................................. 42

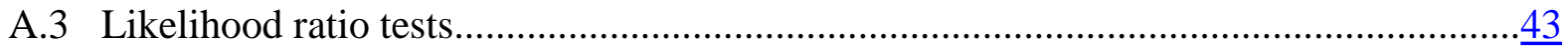

Figures

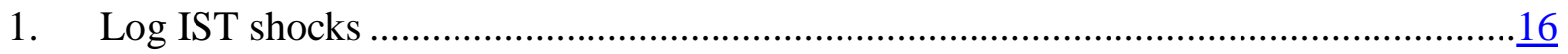

2. Log TPF shocks ..................................................................................... 20

3. Impulse-Responses in the Stationary Model. Note: Thick Solid: M2. Thin Solid: M3. Dashed: M4 $\underline{27}$

4. Impulse-Responses in the Non-Stationary Model. Note: Thick Solid: MsNS. Thin Solid: M2NSb. Dashed: M3NS......................................................................... 


\section{Introduction}

Standard international real business cycle (IRBC) models only driven by total factor productivity (TFP) shocks fail to account for at least four important features of the data. First, cross-country consumption correlations are generally similar to or lower than cross-country output correlations in the data, whereas existing models typically produce much higher consumption correlations than output correlations (the "quantity" puzzle). Second, investment and employment tend to be positively correlated across countries, whereas the models predict a negative correlation (the "international comovement" puzzle). Third, the standard setup predicts that the real exchange rate (RER) is positively linked to the ratio of consumption across the two economies, while instead the correlation in the data is negative or close to zero (the "Backus-Smith" puzzle). Fourth, models generate far less volatility in the terms of trade and the RER than in the data (the "price" puzzle).

Risk sharing across countries induces strong positive cross-country consumption correlations in the IRBC framework. This result still holds even when the complete markets assumption is replaced by incomplete markets. The efficient response to a temporary TFP shock involves increasing factor inputs (investment and labor supply) in the more productive country and reducing factor inputs in the less productive country. The model also dictates that domestic households consume more relative to their foreign counterparts when their consumption basket is relatively cheap (i.e., when the RER increases). Finally, since models produce highly correlated consumption levels, their ratio shows low volatility. Since the RER is directly associated with this ratio, the RER is not very volatile. The accumulation of these effects creates the four puzzles described above.

The literature has been energetically trying to fill this gap between theory and data on some of these dimensions, with some success. For example, Chari et al. (2002) show that a monetary economy with monopolistic competition and sticky prices can solve the "price" puzzle if a high degree of risk aversion is assumed. They also show that in a model with monetary policy shocks only the "Backus-Smith" puzzle cannot be solved regardless of the asset market structure in the model and of the presence of other nominal or real rigidities. Corsetti et al. (2008a and 2008b) show that introducing nontraded goods helps reconcile theory with data on the "price" and "Backus-Smith" puzzle dimensions.

Another alternative is to introduce taste shocks as in Stockman and Tesar (1995) and Heathcote and Perri (2007). In particular, Heathcote and Perri (2007) show how this type of demand shock can successfully address the "Backus-Smith" puzzle. However, it is difficult to measure taste shocks in the data. Raffo (2009) instead considers 
investment-specific technology (IST) shocks, along the guidelines specified in Greenwood et al. (1988) and the empirical work of Fisher (2006), and he successfully addresses the four puzzles. In fact, this type of shock has two appealing features: it resembles a demand shock (given that it directly affects the relative price of capital goods) and it has a clear link to the data. Raffo (2009) cleverly takes advantage of the first feature but does not consider the second. Instead of using the data to parameterize the law of motion of the IST shocks, he thoughtfully calibrates them to match some other observables commonly used in the IRBC literature.

Our paper follows an alternative approach. First, using data from the OECD, we provide evidence that IST processes for the United States (U.S.) and a "rest of the world" (R.W.) aggregate have a unit root and are cointegrated. Motivated by this empirical finding, we estimate a vector error correction model (VECM) for the IST processes of the U.S. and the R.W. Second, we add IST shocks that follow the estimated VECM process into an otherwise standard two-country, two-goods model with TFP also following a VECM process as described in Rabanal et al. (2010). Our model should be considered an extension of Heathcote and Perri (2002) to consider IST shocks (as in Raffo, 2009) and cointegrated shocks (Rabanal et al., 2010). In that sense, our model is closely related to Ireland (2009), who constructs a two-country stochastic growth model with cointegrated TFP and IST shocks to analyze the macroeconomic performance of both the U.S. and the Euro area. Finally, we simulate the model and analyze the results.

Our results indicate that while a calibration of the IST shocks along the lines of Raffo (2009) would suffice to address the above-mentioned puzzles, the data is less supportive. The estimated process for the IST shocks helps in improving model fit along some of these dimensions, but it is unable to fully solve them. Raffo (2009) calibrates the variance of the IST processes to be almost three times the one characterizing the TFP process. In that case, the IST shocks account for about two-thirds of the variation in output. Instead, our estimation results indicate that the variance of the IST process is about the same size as the variance of the TFP innovations, making the IST shocks quantitatively less effective. ${ }^{1}$

Our findings do not change even when we consider additional internal amplification mechanisms such as endogenous capital utilization, which facilitate investment demand booms; or GHH preferences, which suppress the wealth effect responsible for dampening the response of the labor supply to productivity innovations and changes in the terms

\footnotetext{
${ }^{1}$ Behind our exercise lies the assumption that basic IRBC models do a good job fitting the data. Some authors doubt it. For example García-Cicco et. al. (2009) report that the RBC model does a poor job at explaining business cycles in emerging countries. They also find that only a richer model with country premium shocks and financial frictions can account for the business cycles in emerging markets.
} 
of trade.

In addition to the above-described association with the IRBC literature, our work is also related to the growing literature analyzing the usefulness of IST shocks in explaining business cycle fluctuations. As in Altig et al. (2005) and Schmitt-Grohé and Uribe (2008), we find that estimated IST shocks play a minor role in driving business cycle fluctuations. In addition to Raffo's (2009) paper, the lack of thrust of the IST shocks is in conflict with some other studies. For example, Justiniano et al. (2008) estimate that IST shocks are responsible for more than 50 percent of output fluctuations in the U.S. and report a standard deviation of their IST process that is more than four times larger than that of its empirical equivalent. Note, however, that there is a relevant difference between our work and Schmitt-Grohé and Uribe's (2008) work, and that of Justiniano et al. (2008) and Raffo (2009). While both our paper and Schmitt-Grohé and Uribe's estimate the law of motion for IST shocks using the observed relative price of investment, the papers of Justiniano et al. and Raffo do not. Hence, the IST shock can be freely parameterized to fit the properties of other observed macroeconomic variables. But clearly this extra freedom has some empirical implications that are at odds with the data.

The rest of the paper is organized as follows. In section II. we present the model with cointegrated shocks. In section III. we describe our data and report estimates for the law of motion of these processes of the U.S. and a R.W. aggregate. In section IV. we present the main findings from simulating the model, leaving section 5 for concluding remarks.

\section{The Model}

In this section, we present a standard two-country, two-goods IRBC model similar to the one described in Heathcote and Perri (2002). The main difference with respect to the standard IRBC literature is the inclusion of IST shocks and the definition of cointegrated processes for both IST and TFP shocks. Following Raffo (2009), and for comparison purposes, we also introduce endogenous capital utilization as in Greenwood et al. (1988) and a quadratic adjustment cost in the capital stock.

In most of the existing literature, productivity processes (IST and TFP) are assumed to be stationary or trend stationary in logs, and they are modelled as a VAR in levels. ${ }^{2}$ In

\footnotetext{
${ }^{2}$ Some important exceptions are Rabanal et al. (2010), Ireland (2009), and Engel and Matsumoto (2009). It is also important to mention that Baxter and Crucini (1995) was the first paper to consider permanent shocks and the possibility of cointegration in the context of this class of models. The reason they did not pursue the VECM specification was that the evidence of cointegration was mixed for the
} 
this paper, we instead consider (log) processes that are cointegrated of order $\mathrm{C}(1,1)$. This implies that the $(\log )$ processes are integrated of order one but a linear combination is stationary. According to the Granger representation theorem (see Engle and Granger, 1987), our $\mathrm{C}(1,1)$ assumption is equivalent to defining a VECM for the law of motion of the first (log) differences of the technology processes. It is the case that our $\mathrm{C}(1,1)$ assumption has strong data implications. In section $\mathrm{C}$. we provide empirical evidence that supports our hypothesis.

In each country, a single final good is produced by a representative competitive firm that uses intermediate goods in the production process. These intermediate goods are imperfect substitutes for each other and can be purchased from representative competitive producers of intermediate goods in both countries. Intermediate goods producers use local capital and labor in the production process. The final good can only be locally consumed or invested by consumers; hence, all trade between countries occurs at the intermediate goods level. In addition, consumers trade across countries an uncontingent international one-period riskless bond denominated in units of home-country intermediate goods. We thus assume incomplete markets. In each period of time $t$, the economy experiences one of many finite events $s_{t}$. We denote by $s^{t}=\left(s_{0}, \ldots, s_{t}\right)$ the history of events up through period $t$. The probability, as of period 0 , of any particular history $s^{t}$ is $\pi\left(s^{t}\right)$ and $s_{0}$ is given.

In the remainder of this section, we describe the households' problem, the intermediate and final goods producers' problems, and the VECM processes. Then, we detail market clearing and equilibrium. Finally, we discuss the conditions for the existence of a balanced growth path. In Appendices A. and B., we explain how to transform the variables in the model to achieve stationarity.

\section{A. Households}

We describe the decision problem faced by home-country households. The problem faced by foreign-country households is similar, and hence, it is not presented because of space considerations. The representative household of the home-country solves

$$
\max _{\left\{C\left(s^{t}\right), L\left(s^{t}\right), X\left(s^{t}\right), K\left(s^{t}\right), D\left(s^{t}\right), u\left(s^{t}\right)\right\}} \sum_{t=0}^{\infty} \beta^{t} \sum_{s^{t}} \pi\left(s^{t}\right) U\left[C\left(s^{t}\right), L\left(s^{t}\right)\right]
$$

bilateral pairs they studied. 
subject to the following budget constraint:

$$
\begin{gathered}
P\left(s^{t}\right)\left[C\left(s^{t}\right)+X\left(s^{t}\right)\right]+P_{H}\left(s^{t}\right) \bar{Q}\left(s^{t}\right) D\left(s^{t}\right) \leqslant \\
P\left(s^{t}\right)\left[W\left(s^{t}\right) L\left(s^{t}\right)+u\left(s^{t}\right) R\left(s^{t}\right) K\left(s^{t-1}\right)\right]+P_{H}\left(s^{t}\right)\left\{D\left(s^{t-1}\right)-\Phi\left[D\left(s^{t}\right)\right]\right\}
\end{gathered}
$$

and the law of motion for capital:

$K\left(s^{t}\right)=\left\{1-\delta\left[u\left(s^{t}\right)\right]\right\} K\left(s^{t-1}\right)+V\left(s^{t}\right)\left\{X\left(s^{t}\right)-\frac{\phi}{2} X\left(s^{t-1}\right) \frac{V\left(s^{t-1}\right)}{V\left(s^{t}\right)}\left[\frac{X\left(s^{t}\right) V\left(s^{t}\right)}{X\left(s^{t-1}\right) V\left(s^{t-1}\right)}-\Lambda_{X}\right]^{2}\right\}$

$U\left[C\left(s^{t}\right), L\left(s^{t}\right)\right]$ is the period utility function, ${ }^{3} \beta \in(0,1)$ is the discount factor, $L\left(s^{t}\right) \in(0,1)$ is the fraction of time allocated to work in the home-country, $C\left(s^{t}\right) \geq 0$ are units of consumption of the final good, $X\left(s^{t}\right) \geq 0$ are units of investment, and $K\left(s^{t}\right) \geq 0$ is the capital level in the home-country at the beginning of period $t+1$. $P\left(s^{t}\right)$ is the price of the home final good, which will be defined below. $W\left(s^{t}\right)$ is the hourly wage in the home-country and $R\left(s^{t}\right)$ is the home-country rental rate of capital, where both are measured in units of the final good. $P_{H}\left(s^{t}\right)$ is the price of the home intermediate good. The depreciation of the stock of capital, $\delta\left[u\left(s^{t}\right)\right]$, is a function of its utilization rate $u\left(s^{t}\right)$. Following Greenwood et al. (1988) we assume that:

$$
\delta\left[u\left(s^{t}\right)\right]=\bar{\delta}+\frac{b}{1+\varepsilon} u\left(s^{t}\right)^{1+\varepsilon},
$$

where $b \geqslant 0$ and $\varepsilon>0$. The parameter $\varepsilon$ represents the elasticity of marginal depreciation with respect to the utilization rate, and $b$ and $\bar{\delta}$ pin down the rate of utilization and the depreciation rate in the steady state. In order to gain some intuition of the effects of each of the considered features, when analyzing the results we will contemplate models without IST shocks, adjustment cost in the capital stock, or an endogenous capital utilization. In particular, when we consider models without a utilization rate of capital, $u\left(s^{t}\right)$ will be set at 1 and $\delta\left[u\left(s^{t}\right)\right]=\delta(1)=\bar{\delta}+\frac{b}{1+\varepsilon}$ for all $s^{t}$ and all $t$.

The parameter $\phi$ controls the elasticity of the adjustment cost in the capital stock to changes in investment. When we consider models without costs of adjustment in the capital stock, $\phi$ will be set to zero.

$V\left(s^{t}\right)$ is the IST shock. In a competitive equilibrium, $V\left(s^{t}\right)^{-1}$ is interpreted as the relative price of capital goods with respect to the price of consumption goods. We will

\footnotetext{
${ }^{3}$ We will consider two types of utility functions when analyzing the results in Section IV.. The standard Cobb-Douglas case, as in Heathcote and Perri (2002), and the GHH preferences as in Raffo (2009).
} 
also consider models without IST shocks when analyzing the results. In that case, we will set $V\left(s^{t}\right)=1$ for all $s^{t}$ and all $t$.

The presence of two unit roots makes the model non-stationary (a non-stationary TFP shock will be introduced later). Hence, we rescale the adjustment cost to account for the long-run gross rate of growth of investment along the balanced growth path: $\Lambda_{X}$ (also to be defined later). $D\left(s^{t}\right)$ denotes the holdings of the internationally traded riskless bond that pays one unit of the home-country intermediate good (minus a small cost of holding bonds, $\Phi(\cdot))$ in period $t+1$ regardless of the state of nature. $\bar{Q}\left(s^{t}\right)$ is its price, measured in units of the home intermediate good. Finally, the function $\Phi(\cdot)$ is the arbitrarily small cost of holding bonds measured in units of the home intermediate good. ${ }^{4}$ Following the existing literature, we assume that $\Phi(\cdot)$ takes the following functional form:

$$
\Phi\left[D\left(s^{t}\right)\right]=\frac{\varsigma}{2} Z\left(s^{t-1}\right)\left[\frac{D\left(s^{t}\right)}{Z\left(s^{t-1}\right)}\right]^{2} .
$$

We need to include $Z\left(s^{t-1}\right)$ in the adjustment cost function, both dividing $D\left(s^{t}\right)$ and multiplying $\left[\frac{D\left(s^{t}\right)}{Z\left(s^{t-1}\right)}\right]^{2}$ where $Z\left(s^{t}\right)=A\left(s^{t}\right)^{\frac{1}{1-\alpha}} V\left(s^{t}\right)^{\frac{\alpha}{1-\alpha}}$ and $A\left(s^{t}\right)$ is the home-country TFP shock. The reason is that $D\left(s^{t}\right)$ will grow at the rate of growth of $Z\left(s^{t-1}\right)$ along the balanced growth path, making the ratio $\frac{D\left(s^{t}\right)}{Z\left(s^{t-1}\right)}$ stationary. Also, since the home-country intermediate good will also grow at the same rate of $Z\left(s^{t-1}\right)$ along the balanced growth path, we need to make the adjustment cost (measured in units of the home intermediate good) grow at that rate in order to induce stationarity.

\section{B. Firms}

\section{B.1 Final goods producers}

The final good in the home-country, $Y\left(s^{t}\right)$, is produced using home intermediate goods, $Y_{H}\left(s^{t}\right)$, and foreign intermediate goods, $Y_{F}\left(s^{t}\right)$, with the following technology:

$$
Y\left(s^{t}\right)=\left[\omega^{\frac{1}{\theta}} Y_{H}\left(s^{t}\right)^{\frac{\theta-1}{\theta}}+(1-\omega)^{\frac{1}{\theta}} Y_{F}\left(s^{t}\right)^{\frac{\theta-1}{\theta}}\right]^{\frac{\theta}{\theta-1}}
$$

where $\omega$ denotes the fraction of home intermediate goods that are used for the production of the home final good and $\theta$ represents the elasticity of substitution between home and foreign intermediate goods. Therefore, the representative final goods

\footnotetext{
${ }^{4}$ The $\Phi(\cdot)$ cost is introduced to ensure stationarity of the level of $D\left(s^{t}\right)$ in IRBC models with incomplete markets, as discussed by Heathcote and Perri (2002). We choose the cost to be numerically small, so it does not affect the dynamics of the rest of the variables.
} 
producer in the home-country solves the following problem:

$$
\max _{Y\left(s^{t}\right) \geq 0, Y_{H}\left(s^{t}\right) \geq 0, Y_{F}\left(s^{t}\right) \geq 0} P\left(s^{t}\right) Y\left(s^{t}\right)-P_{H}\left(s^{t}\right) Y_{H}\left(s^{t}\right)-P_{F}\left(s^{t}\right) Y_{F}\left(s^{t}\right)
$$

subject to the production function (4), where $P_{F}\left(s^{t}\right)$ is the price of the foreign intermediate good in the home country.

\section{B.2 Intermediate goods producers}

The representative intermediate goods producer in the home-country uses home labor and capital in order to produce home intermediate goods and sells her product to both the home and the foreign final good producers. Taking prices of all goods and factor inputs as given, she maximizes profits. Hence, she solves:

$\underset{L\left(s^{t}\right) \geq 0, K\left(s^{t-1}\right) \geq 0}{\operatorname{Max}} P_{H}\left(s^{t}\right)\left[Y_{H}\left(s^{t}\right)+Y_{H}^{*}\left(s^{t}\right)\right]-P\left(s^{t}\right)\left[W\left(s^{t}\right) L\left(s^{t}\right)+u\left(s^{t}\right) R\left(s^{t}\right) K\left(s^{t-1}\right)\right]$

subject to the production function:

$$
G D P\left(s^{t}\right)=Y_{H}\left(s^{t}\right)+Y_{H}^{*}\left(s^{t}\right)=A\left(s^{t}\right)\left[u\left(s^{t}\right) K\left(s^{t-1}\right)\right]^{\alpha} L\left(s^{t}\right)^{1-\alpha}
$$

where $Y_{H}\left(s^{t}\right)$ is the amount of home intermediate goods sold to the home final goods producers, $Y_{H}^{*}\left(s^{t}\right)$ is the amount of home intermediate goods sold to the foreign final goods producers, and $A\left(s^{t}\right)$ is the TFP shock, which we will characterize below. $G D P\left(s^{t}\right)$ is the home-country gross domestic product or home-country output. Throught the text we use the concepts output or GDP to refer to the $G D P\left(s^{t}\right)$ variable.

\section{B.3 The VECMs for IST and TFP Shocks}

As mentioned above, we depart from the standard assumption in the IRBC literature and consider processes for both IST and TFP shocks that are cointegrated of order $C(1,1)$ and hence follow a VECM specification.

We specify the following VECM for the law of motion driving the (log) differences of the IST $(V)$ and TFP $(A)$ stochastic processes for both the home and the foreign country:

$\left(\begin{array}{c}\Delta \log \digamma\left(s^{t}\right) \\ \Delta \log \digamma^{*}\left(s^{t}\right)\end{array}\right)=\left(\begin{array}{c}c_{\digamma} \\ c_{\digamma^{*}}\end{array}\right)+\left(\begin{array}{c}\kappa_{\digamma} \\ \kappa_{\digamma^{*}}\end{array}\right)\left[\log \digamma\left(s^{t-1}\right)-\gamma_{\digamma} \log \digamma^{*}\left(s^{t-1}\right)-\log \xi_{\digamma}\right]+\left(\begin{array}{c}\varepsilon^{\digamma}\left(s^{t}\right) \\ \varepsilon^{\digamma^{*}}\left(s^{t}\right)\end{array}\right)$

where $\digamma=\{V, A\},\left(1,-\gamma_{\digamma}\right)$ is the cointegrating vector and $\xi_{\digamma}$ is the constant in the cointegrating relationship. The shocks $\varepsilon^{\digamma}\left(s^{t}\right) \sim N\left(0, \sigma^{\digamma}\right)$ and $\varepsilon^{\digamma^{*}}\left(s^{t}\right) \sim N\left(0, \sigma^{\digamma^{*}}\right)$ are 
correlated, and $\Delta$ is the first-difference operator. We restrict ourselves to a VECM with zero lags. This assumption is motivated by the empirical results to be presented below.

\section{Market Clearing}

The model is closed with the following market clearing conditions which equates the aggregate demand (domestic absorption) with total production in the final goods markets:

$$
C\left(s^{t}\right)+X\left(s^{t}\right)=Y\left(s^{t}\right) \text { and } C^{*}\left(s^{t}\right)+X^{*}\left(s^{t}\right)=Y^{*}\left(s^{t}\right),
$$

and the bond market:

$$
D\left(s^{t}\right)+D^{*}\left(s^{t}\right)=0 .
$$

\section{Equilibrium and Equilibrium Conditions}

Given our laws of motion for shocks defined in section B.3, an equilibrium for this economy is a set of allocations for home consumers, $C\left(s^{t}\right), L\left(s^{t}\right), K\left(s^{t}\right), X\left(s^{t}\right), u\left(s^{t}\right)$, and $D\left(s^{t}\right)$, and foreign consumers, $C^{*}\left(s^{t}\right), L^{*}\left(s^{t}\right), K^{*}\left(s^{t}\right), X^{*}\left(s^{t}\right), u^{*}\left(s^{t}\right)$, and $D^{*}\left(s^{t}\right)$, allocations for home and foreign intermediate goods producers, $Y_{H}\left(s^{t}\right), Y_{H}^{*}\left(s^{t}\right)$, $Y_{F}\left(s^{t}\right)$ and $Y_{F}^{*}\left(s^{t}\right)$, allocations for home and foreign final goods producers, $Y\left(s^{t}\right)$ and $Y^{*}\left(s^{t}\right)$, intermediate goods prices $P_{H}\left(s^{t}\right), P_{H}^{*}\left(s^{t}\right), P_{F}\left(s^{t}\right)$ and $P_{F}^{*}\left(s^{t}\right)$, final goods prices $P\left(s^{t}\right)$ and $P^{*}\left(s^{t}\right)$, rental prices of labor and capital in the home and foreign-country, $W\left(s^{t}\right), R\left(s^{t}\right), W^{*}\left(s^{t}\right)$, and $R^{*}\left(s^{t}\right)$ and the price of the bond $\bar{Q}\left(s^{t}\right)$ such that $(i)$ given prices, household allocations solve the households' problem; (ii) given prices, intermediate goods producers allocations solve the intermediate goods producers' problem; (iii) given prices, final goods producers allocations solve the final goods producers' problem; $(i v)$ and markets clear.

\section{D.1 Equilibrium conditions}

It is useful to define the following relative prices: $\widetilde{P}_{H}\left(s^{t}\right)=\frac{P_{H}\left(s^{t}\right)}{P\left(s^{t}\right)}, \widetilde{P}_{F}^{*}\left(s^{t}\right)=\frac{P_{F}^{*}\left(s^{t}\right)}{P^{*}\left(s^{t}\right)}$ and $R E R\left(s^{t}\right)=\frac{P^{*}\left(s^{t}\right)}{P\left(s^{t}\right)}$. Note that $\widetilde{P}_{H}\left(s^{t}\right)$ is the price of home intermediate goods in terms of home final goods, $\widetilde{P}_{F}^{*}\left(s^{t}\right)$ is the price of foreign intermediate goods in terms of foreign final goods, which appears in the foreign-country's budget constraint, and $R E R\left(s^{t}\right)$ is the RER between the home and foreign countries. In our model the law of one price holds; hence, we have that $P_{H}\left(s^{t}\right)=P_{H}^{*}\left(s^{t}\right)$ and $P_{F}\left(s^{t}\right)=P_{F}^{*}\left(s^{t}\right)$. In the model the only source of RER fluctuations is the presence of home bias. 
We now determine the equilibrium conditions implied by the first-order conditions of households, intermediate and final goods producers in the home-country, as well as the relevant laws of motion, production functions, and market clearing conditions. The conditions in the foreign-country are symmetrical and not described here because of space considerations. The marginal utility of consumption and the labor supply are given by:

$$
\begin{aligned}
& U_{C}\left[C\left(s^{t}\right), L\left(s^{t}\right)\right]=\lambda\left(s^{t}\right), \\
& \frac{U_{L}\left[C\left(s^{t}\right), L\left(s^{t}\right)\right]}{U_{C}\left[C\left(s^{t}\right), L\left(s^{t}\right)\right]}=W\left(s^{t}\right),
\end{aligned}
$$

where $U_{x}$ denotes the partial derivative of the utility function $U$ with respect to variable $x$. The first-order conditions with respect to capital and investment deliver:

$$
\mu\left(s^{t}\right)=\beta \sum_{s^{t+1}} \pi\left(s^{t+1} / s^{t}\right)\left\{u\left(s^{t+1}\right) R\left(s^{t+1}\right) \lambda\left(s^{t+1}\right)+\mu\left(s^{t+1}\right)\left(1-\delta\left(u\left(s^{t+1}\right)\right)\right)\right\}
$$

and

$$
\begin{gathered}
\lambda\left(s^{t}\right)=\mu\left(s^{t}\right) V\left(s^{t}\right)(1-\phi(\Omega(t))) \\
+\beta \sum_{s^{t+1}} \pi\left(s^{t+1} / s^{t}\right) \mu\left(s^{t+1}\right) V\left(s^{t+1}\right)\left[\phi(\Omega(t+1)) \frac{X\left(s^{t+1}\right)}{X\left(s^{t}\right)}-\frac{\phi}{2} \frac{V\left(s^{t}\right)}{V\left(s^{t+1}\right)}(\Omega(t+1))^{2}\right]
\end{gathered}
$$

where $\Omega(t)=\frac{X\left(s^{t}\right) V\left(s^{t}\right)}{X\left(s^{t-1}\right) V\left(s^{t-1}\right)}-\Lambda_{X}$, and $\pi\left(s^{t+1} \mid s^{t}\right)=\frac{\pi\left(s^{t+1}\right)}{\pi\left(s^{t}\right)}$ is the conditional probability of $s^{t+1}$ given $s^{t}$. When we consider models without an adjustment cost of capital, equation (9) will be substituted by:

$$
\lambda\left(s^{t}\right)=\mu\left(s^{t}\right) V\left(s^{t}\right)
$$

When we consider models without IST shocks we will set $V\left(s^{t}\right)=1$ for all $s^{t}$ and $t$ in either equation (9) or equation (10) depending on whether we are considering models with or without an adjustment cost of capital.

The first-order condition with respect the capital utilization rate is:

$$
\lambda\left(s^{t}\right) R\left(s^{t}\right)=\mu\left(s^{t}\right) \delta^{\prime}\left(u\left(s^{t}\right)\right)
$$

where, if we take into account the parametrization of $\delta\left(u\left(s^{t}\right)\right)$, we have:

$$
\lambda\left(s^{t}\right) R\left(s^{t}\right)=b \mu\left(s^{t}\right) u\left(s^{t}\right)^{\varepsilon} .
$$

When we consider models without a capital utilization rate, this first-order condition 
will not be considered and we will set $u\left(s^{t}\right)=1$ for all $s^{t}$ and $t$. Also, when this is the case, $\delta\left(u\left(s^{t}\right)\right)$ will be set equal to $\delta(1)$ for all $s^{t}$ and $t$ in equation (8).

The optimal choice by households in the home-country with respect to the riskless bond delivers the following expression for its price

$$
\bar{Q}\left(s^{t}\right)=\beta \sum_{s^{t+1}} \pi\left(s^{t+1} \mid s^{t}\right) \frac{\lambda\left(s^{t+1}\right)}{\lambda\left(s^{t}\right)} \frac{\widetilde{P}_{H}\left(s^{t+1}\right)}{\widetilde{P}_{H}\left(s^{t}\right)}-\Phi^{\prime}\left[D\left(s^{t}\right)\right] .
$$

The risk-sharing condition is given by the optimal choice of the households of both countries for the riskless bond:

$$
\sum_{s^{t+1}} \pi\left(s^{t+1} \mid s^{t}\right)\left[\frac{\lambda^{*}\left(s^{t+1}\right)}{\lambda^{*}\left(s^{t}\right)} \frac{\widetilde{P}_{H}\left(s^{t+1}\right)}{\widetilde{P}_{H}\left(s^{t}\right)} \frac{R E R\left(s^{t}\right)}{R E R\left(s^{t+1}\right)}-\frac{\lambda\left(s^{t+1}\right)}{\lambda\left(s^{t}\right)} \frac{\widetilde{P}_{H}\left(s^{t+1}\right)}{\widetilde{P}_{H}\left(s^{t}\right)}\right]=-\frac{\Phi^{\prime}\left[D\left(s^{t}\right)\right]}{\beta} .
$$

We assume that foreigners do not face portfolio adjustment costs. From the intermediate goods producers' maximization problems, we obtain the result that labor and capital are paid their marginal product, where the rental rate of capital and the real wage are expressed in terms of the final good in each country:

$$
W\left(s^{t}\right)=(1-\alpha) \widetilde{P}_{H}\left(s^{t}\right) A\left(s^{t}\right)\left[u\left(s^{t}\right) K\left(s^{t-1}\right)\right]^{\alpha} L\left(s^{t}\right)^{-\alpha}
$$

and

$$
R\left(s^{t}\right)=\alpha \widetilde{P}_{H}\left(s^{t}\right) A\left(s^{t}\right)\left[u\left(s^{t}\right) K\left(s^{t-1}\right)\right]^{\alpha-1} L\left(s^{t}\right)^{1-\alpha} .
$$

From the final goods producers' maximization problem, we obtain the demands of intermediate goods, which depend on their relative price:

$$
Y_{H}\left(s^{t}\right)=\omega \widetilde{P}_{H}\left(s^{t}\right)^{-\theta} Y\left(s^{t}\right)
$$

and

$$
Y_{F}\left(s^{t}\right)=(1-\omega)\left(\widetilde{P}_{F}^{*}\left(s^{t}\right) R E R\left(s^{t}\right)\right)^{-\theta} Y\left(s^{t}\right) .
$$

Finally, the goods, inputs, and bond markets clear. Thus:

$$
\begin{gathered}
C\left(s^{t}\right)+X\left(s^{t}\right)=Y\left(s^{t}\right) \\
Y\left(s^{t}\right)=\left[\omega^{\frac{1}{\theta}} Y_{H}\left(s^{t}\right)^{\frac{\theta-1}{\theta}}+(1-\omega)^{\frac{1}{\theta}} Y_{F}\left(s^{t}\right)^{\frac{\theta-1}{\theta}}\right]^{\frac{\theta}{\theta-1}}, \\
Y_{H}\left(s^{t}\right)+Y_{H}^{*}\left(s^{t}\right)=A\left(s^{t}\right)\left[u\left(s^{t}\right) K\left(s^{t-1}\right)\right]^{\alpha} L\left(s^{t}\right)^{1-\alpha},
\end{gathered}
$$


and

$$
D\left(s^{t}\right)+D^{*}\left(s^{t}\right)=0 .
$$

The law of motion of the level of debt is:

$$
\begin{aligned}
\widetilde{P}_{H}\left(s^{t}\right) \bar{Q}\left(s^{t}\right) D\left(s^{t}\right)= & \widetilde{P}_{H}\left(s^{t}\right) Y_{H}^{*}\left(s^{t}\right)-\widetilde{P}_{F}^{*}\left(s^{t}\right) R E R\left(s^{t}\right) Y_{F}\left(s^{t}\right) \\
& +\widetilde{P}_{H}\left(s^{t}\right) D\left(s^{t-1}\right)-\widetilde{P}_{H}\left(s^{t}\right) \Phi\left[D\left(s^{t}\right)\right],
\end{aligned}
$$

and it is obtained using (2) and the fact that intermediate and final goods producers at home make zero profits. Finally, the laws of motion for shocks are as defined in section B.3.

\section{E. Balanced Growth and the Restriction on the Cointegrating Vector}

Equations (6) to (22) and the VECM processes defined in section B.3, together with analogous conditions for foreign country households, intermediate and final goods producers, characterize the equilibrium in this model. Since we assume that both pairs $\left(\log A\left(s^{t}\right), \log A^{*}\left(s^{t}\right)\right)$ and $\left(\log V\left(s^{t}\right), \log V^{*}\left(s^{t}\right)\right)$ are cointegrated processes, we need to normalize the equilibrium conditions in order to obtain a stationary system more amenable to study.

The basic idea is to divide most of the home-country variables that have a trend by $Z\left(s^{t-1}\right)$, where $Z\left(s^{t}\right)=A\left(s^{t}\right)^{\frac{1}{1-\alpha}} V\left(s^{t}\right)^{\frac{\alpha}{1-\alpha}}$, and the foreign-country variables by $Z^{*}\left(s^{t-1}\right)$, where $Z^{*}\left(s^{t}\right)=A^{*}\left(s^{t}\right)^{\frac{1}{1-\alpha}} V^{*}\left(s^{t}\right)^{\frac{\alpha}{1-\alpha}}$. One exception is the capital stocks, which are instead divided by $Z\left(s^{t-1}\right) V\left(s^{t-1}\right)$ and $Z^{*}\left(s^{t-1}\right) V^{*}\left(s^{t-1}\right)$ respectively. In Appendices A. and B., we detail the full set of normalized equilibrium conditions for the Cobb-Douglas and the GHH cases.

For the model to have balanced growth we require some restrictions on preferences, production functions, and the law of motion of the shocks. The restrictions on preferences and technology of King et al. (1988) are sufficient for the existence of balanced growth in a closed economy real business cycle (RBC) model. However, in our two-country model, an additional restriction on the cointegrating vector is needed if the model is to exhibit balanced growth. In particular, we need the ratio $Z\left(s^{t-1}\right) / Z^{*}\left(s^{t-1}\right)$ to be stationary. For example, if the ratio $Z\left(s^{t-1}\right) / Z^{*}\left(s^{t-1}\right)$ were to be non-stationary, the ratio between $Y_{F}\left(s^{t}\right)$ and $Y_{F}^{*}\left(s^{t}\right)$ would also be non-stationary, and consequently, the balanced growth path would not exist. A sufficient condition to guarantee the stationarity of $Z\left(s^{t-1}\right) / Z^{*}\left(s^{t-1}\right)$ is to check for the stationarity of both $A\left(s^{t-1}\right) / A^{*}\left(s^{t-1}\right)$ and $V\left(s^{t-1}\right) / V^{*}\left(s^{t-1}\right)$. Rabanal et al. (2010) indeed show that the first ratio (TFP processes) is stationary. In what follows we focus the analysis on the IST shocks. 
When analyzing the results in section IV., we will also consider models in which both IST and TFP shocks are stationary. This is necessary to compare our results with those in the existing literature. In this case, we will not need to normalize the equilibrium conditions (6) to (22). When this is the case, the VECM processes defined in section B.3 will have to be replaced. In section IV. we will define the alternative stationary processes to be considered.

\section{Estimation of the VECMs for IST Shocks}

We present estimates of our VECMs for IST and TFP shocks in this section. First, we use series for the relative price of investment for the U.S. and the R.W. to build our IST shocks. Then, we show that our assumption that the IST processes are cointegrated of order $\mathrm{C}(1,1)$ cannot be rejected in the data. Next, we show that the restriction that the parameter $\gamma_{V}$ be equal to one cannot be rejected in the data.

Rabanal et al. (2010) show that same conclusions apply to the TFP processes. Consequently, the fact that $\gamma_{V}$ and $\gamma_{A}$ are both statistically not different from one implies that we cannot reject the existence of balanced growth. For space considerations in this section we briefly discuss the data and report the point estimates of the parameters of the VECM for the TFP shocks. We postpone to the Appendix C. other details.

\section{A. Data for the IST Shocks}

In order to estimate our VECM for (log) IST shocks we use data for the U.S. and an aggregate for the R.W. The R.W. is composed of the U.S.'s most significant trading partners: the 15 countries of the Euro area, Canada, Japan, the United Kingdom, Australia and South Korea. Our sample period goes from 1982:4 to 2007:4. Both for the U.S. and for the R.W., we aim to build $V\left(s^{t}\right)$ using data on investment and consumption deflators.

In particular, for the U.S. the IST shock is defined as

$$
V\left(s^{t}\right)=P C E_{t}^{U . S \cdot} / P I_{t}^{U . S .}
$$

where $P C E_{t}^{U . S .}$ is the personal consumption expenditures deflator, and $P I_{t}^{U . S .}$ is the 


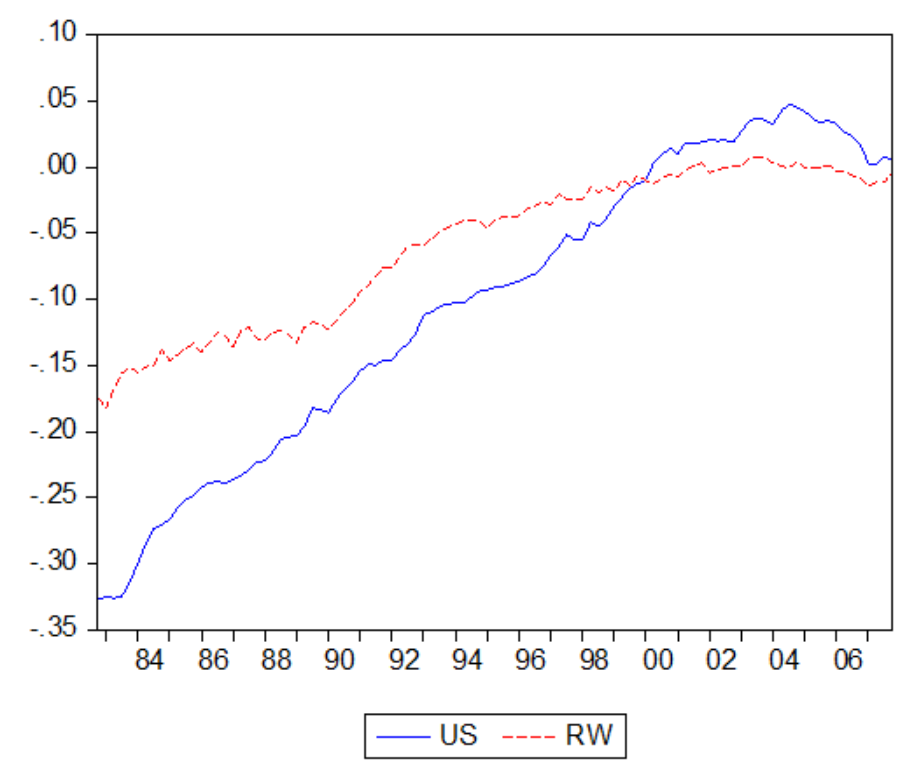

Figure 1: Log IST shocks.

investment deflator. For the R.W. aggregate, we define the IST shock as:

$$
V^{*}\left(s^{t}\right)=\sum_{i} w_{t}^{i} *\left(\frac{P C E_{t}^{i}}{P I_{t}^{i}}\right)
$$

where $i$ identifies the country in the set $\{15$ countries of the Euro area, Canada, Japan, the United Kingdom, Australia and South Korea $\}$ and $w_{t}^{i}$ is the trade weight of a particular country $i$ at time $t$. The weights are the currency weights used in the Broad Index of the Foreign Exchange Value of the dollar calculated by the U.S. Federal Reserve. In Figure 1 we plot the resulting series.

The particular deflators being used are now described. For the U.S. we use the Personal Consumption Expenditure (PCE) deflator as our consumption deflator and the Gross Domestic Investment deflator as our investment deflator. Both series are derived directly from the National Income and Product Accounts (NIPA) and provided by the Bureau of Economic Analysis (BEA). For Japan, we employ the Private final consumption expenditure and the Private-sector capital formation deflator series obtained from the Cabinet Office. In the case of Canada, we use the Personal expenditure on consumer goods and services deflator and the Business gross fixed capital formation deflator series. Both series can be obtained from Canada's statistical agency, Statistics Canada. For the UK, we use the Final consumption expenditure deflator and the Gross fixed capital formation deflator taken from the UK national 
statistics. The deflators for Australia are derived from the Australian Bureau of Statistics. The particular series used were the Households final Consumption Expenditure and the Gross Fixed Capital formation implicit price deflators. For South Korea we use the Final Consumption Expenditure deflator and Gross Capital Formation deflator series retrieved from the Navi-Data database provided by the Korean National Statistical Office. Finally, for the EMU-15 countries, we employ the Consumption Deflator and the Gross Investment deflator from the AWM Database constructed by the European Central Bank.

\section{B. Integration and Cointegration Properties of the IST Shocks}

In this section, we present evidence supporting our assumption that the (log) IST processes for the U.S. and the R.W. are cointegrated of order $\mathrm{C}(1,1)$. We will first empirically support the unit root assumption for the univariate processes and then we will test for the presence of cointegrating relationships using the Johansen (1991) procedure.

Table 1 presents unit root test results for the $(\log )$ IST processes for the U.S. and R.W. The lag length is chosen using the Schwarz criterion. In each case a constant and a trend are included in the specification. None of the tests can reject the null hypothesis of unit root at the 5 percent critical value. Using the same tests, there is also strong evidence that the first difference of the (log) IST processes for the U.S. is stationary. All the tests reject the null hypothesis of a unit root at the 5 percent critical value. For the R.W. the evidence of stationarity of the first difference is weaker. Only the ADF test rejects clearly at the 5 percent. The rest of the tests cannot reject. So, there is strong evidence that the $(\log )$ IST process for the R.W. is integrated, but it is hard to clarify whether it is integrated of order one or two. Given that there is strong evidence that the $(\log )$ IST processes for the U.S. are integrated of order one and, as we show below, there is also strong evidence of a cointegration relationship between the (log) IST processes for the U.S. and the R.W., we take the evidence presented here as evidence in favor of the (log) IST process for the R.W. being integrated of order one. 
Table 1: Unit Root Tests for IST Shocks

\begin{tabular}{lcccc}
\hline \hline & log IST U.S. & \multicolumn{2}{c}{$\log$ IST R.W. } \\
\hline Method & $\begin{array}{c}\text { Level } \\
\text { statistic }\end{array}$ & $\begin{array}{c}\text { First Diff. } \\
\text { statistic }\end{array}$ & $\begin{array}{c}\text { Level } \\
\text { statistic }\end{array}$ & $\begin{array}{c}\text { First Diff. } \\
\text { statistic }\end{array}$ \\
\hline ADF & $1.54^{+}$ & -7.85 & $-0.49^{+}$ & -3.60 \\
DF-GLS & $0.02^{+}$ & -7.11 & $-1.04^{+}$ & $-2.46^{+}$ \\
P $_{T^{-}}$GLS & $103.87^{+}$ & 2.37 & $35.41^{+}$ & $30.03^{+}$ \\
MZ $_{\alpha}$ & $-0.02^{+}$ & -44.38 & $-5.18^{+}$ & $-1.90^{+}$ \\
MZ $_{t}$ & $-0.01^{+}$ & -4.70 & $-1.38^{+}$ & $-0.95^{+}$ \\
\hline MSB & $0.35^{+}$ & 0.11 & $0.26^{+}$ & $0.50^{+}$ \\
\hline \hline
\end{tabular}

Notes: ADF stands for augmented Dickey-Fuller test. DF-GLS stands for Elliott-Rothenberg-Stock detrended residuals test statistic. PT-GLS stands for Elliott-Rothenberg-Stock Point-Optimal test statistic. $\mathrm{MZ}_{\alpha}, \mathrm{MZ}_{t}$, and MSB stand for the class of modified tests analyzed in Ng-Perron (2001) For ADF and DF-GLS we present t-Statistics, for P T-GLS we present P-Statistics and for the $\mathrm{MZ}_{\alpha}, \mathrm{MZ}_{t}$, and MSB we present the $\mathrm{Ng}$-Perron test statistics.

+ denotes Null Hypothesis of unit root not rejected at 5 percent level.

Once we have presented evidence that indicates that the (log) IST for the U.S. and the R.W. is well characterized by integrated processes of order one, we now focus on presenting evidence supporting our assumption that the processes are cointegrated. We consider an unrestricted VAR with one lag and a deterministic trend for the two-variables system $\left[\log V\left(s^{t}\right), \log V^{*}\left(s^{t}\right)\right]$ where the number of lags was chosen using the Schwarz criterion. The absolute value for the two eigenvalues of the VAR implied by the point estimates are 0.98 and 0.88 . If $\log V\left(s^{t}\right)$ and $\log V^{*}\left(s^{t}\right)$ share one common stochastic trend (balanced growth), the estimated VAR has to have a single eigenvalue equal to one and all other eigenvalues have to be less than one. Point estimates are in accord with this prediction. But this is not a formal test of cointegration. Table 2 reports results from the unrestricted cointegration rank test using the trace and the maximum eigenvalue methods as defined by Johansen (1991). We assume no VAR intercept but a constant in the cointegration relationship and zero lags. ${ }^{5}$ Clearly, the data strongly support a single cointegration vector.

Table 2: Cointegration Statistics II: Johansen's Test

\begin{tabular}{ccccc}
\hline \hline Number of Vectors & Trace & p-value & Max-Eigenvalue & p-value \\
\hline 0 & 62.61 & 0.00 & 56.75 & 0.00 \\
1 & 5.85 & 0.20 & 5.85 & 0.21 \\
\hline \hline
\end{tabular}

\footnotetext{
${ }^{5}$ The Johansen (1991) test rejects the existence of a cointegration relationship if we allow for a trend in the VAR or we do not allow for a constant in the cointegration relationship.
} 


\section{The Estimated VECM for IST Shocks}

In the last subsection, we presented evidence that $\log V\left(s^{t}\right)$ and $\log V^{*}\left(s^{t}\right)$ are cointegrated of order $\mathrm{C}(1,1)$. In this subsection we show that the null hypothesis of $\gamma_{V}=1$ cannot be rejected by the data. In fact, the LR test for the null hypothesis $\gamma_{V}=1$ is distributed as a Chi-squared with one degree of freedom and takes value 1.1, clearly smaller than the 5 percent critical value of 3.84. Conditional on this restriction and assuming zero lags, the VECM estimates are reported in Table $4 .^{6}$

Table 3: The VECM for IST

$\frac{\text { Table 3: The VECM for IST }}{\kappa_{V}}$
$\begin{array}{cc}-0.035^{+} & \kappa_{V}^{*} \\ (-8.26) & -0.017^{+} \\ \text {t-statistics in parenthesis. }+ \text { denotes significance at a } 5 \text { percent level. }\end{array}$

Finally, the standard deviation of the innovations $\varepsilon^{V}\left(s^{t}\right)$ and $\varepsilon^{V^{*}}\left(s^{t}\right)\left(\sigma^{V}\right.$ and $\left.\sigma^{V^{*}}\right)$ are estimated to be 0.0051 and 0.0052 , respectively. In the simulation, we will assume that $\varepsilon^{V}\left(s^{t}\right)$ and $\varepsilon^{V^{*}}\left(s^{t}\right)$ are uncorrelated, since this null hypothesis cannot be rejected in the data.

\section{The Estimated VECM for TFP Shocks}

In order to estimate the VECM for the TFP process, Rabanal et al. (2010) use data for the U.S. and an aggregate for the R.W. For the U.S., they use quarterly real GDP data from the Bureau of Economic Analysis and hours and employment data from the Organization for Economic Cooperation and Development (OECD). Real capital stock data is also obtained from the OECD. The R.W. aggregate is defined to be the 15 countries of the Euro area, the United Kingdom, Canada, Japan, and Australia. For the United Kingdom, Canada, Japan, and Australia they obtain nominal GDP, hours, employment, and real capital stock from the OECD. For the Euro area they take nominal GDP, employment, and real capital stock from AWM. Hours are as reported in Christoffel et al. (2009). The sample period goes from 1973:1 to 2006:4, which is when the hours series for the Euro area ends. Details about aggregation of R.W. data are provided in the Appendix C.. In Figure 2 we plot the resulting series.

\footnotetext{
${ }^{6}$ We do normalize the $(\log )$ IST shocks so that the constant takes a value equal to zero. Hence, we do not report it.
} 


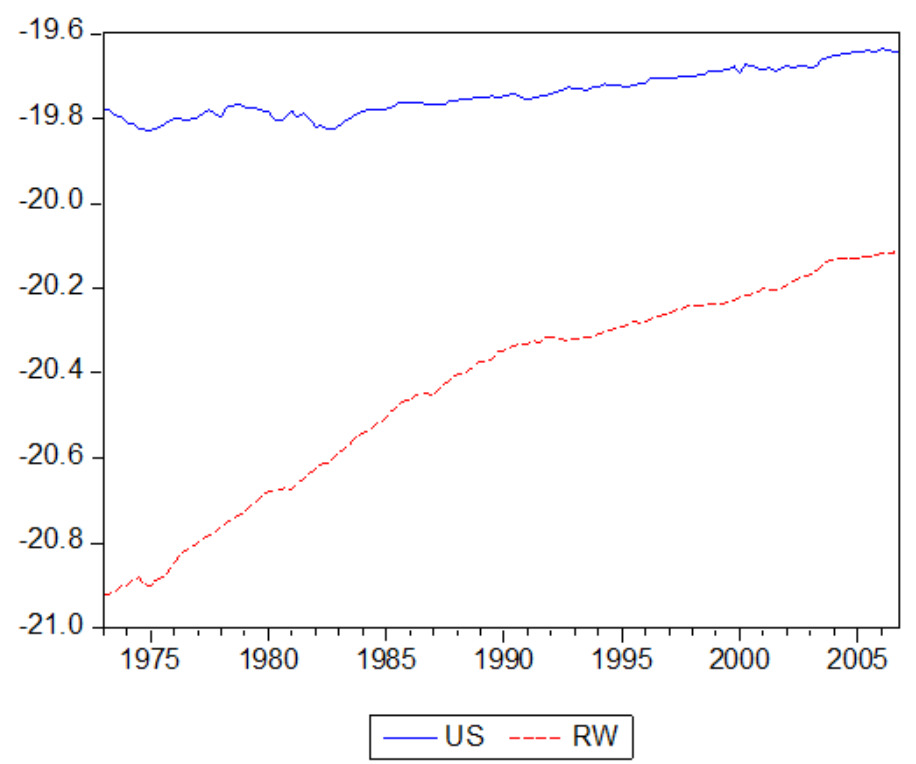

Figure 2: Log TFP Shocks

Rabanal et al. (2010) also present evidence supporting our assumption that the (log) TFP processes for the U.S. and the R.W. are cointegrated of order $\mathrm{C}(1,1)$ and estimate the restricted VECM with zero lags (corresponding to one lag in the VAR as the Schwarz information criterion suggests). The estimated restricted model delivers the parameter estimates reported in Table 4. They use the likelihood ratio test to present evidence supporting the null hypothesis that the coefficients related to the speed of adjustment in the cointegrating vector are equal and of opposite sign, i.e., $\kappa_{A}=-\kappa_{A}^{*}$. It is worth noting that the coefficient of the speed of adjustment, while significant, is quantitatively small, denoting that (log) TFP processes converge slowly over time. The constant terms $c$ and $c^{*}$ are estimated to be different. However, this does not imply that the growth rates of both (log) TFP processes are different. Indeed, because the cointegrating vector is $(1,-1)$ they must grow at the same rate along the balanced growth path. Given the parameter estimates, the implied long run growth rate of (log) TFP processes is 1.44 percent (in annualized terms).

Table 4: VECM model

\begin{tabular}{lcc}
\hline \hline$c_{A}$ & $c_{A^{*}}$ & $\kappa_{A}$ \\
\hline $0.001^{\diamond}$ & $\begin{array}{c}0.006^{+} \\
(1.76)\end{array}$ & $\begin{array}{c}-0.007^{+} \\
(12.46)\end{array}$ \\
\hline \hline
\end{tabular}

t-statistics in parenthesis. ${ }^{+}$denotes significance at the 5 percent level and $\diamond$ denotes significance at the 10 percent level. 
Finally, they also estimate the standard deviation of the innovations $\sigma^{A}$ to be 0.0067 and $\sigma^{A^{*}}$ equal to 0.0056. In our simulations, we will also assume that $\varepsilon^{A}\left(s^{t}\right)$ and $\varepsilon^{A^{*}}\left(s^{t}\right)$ are uncorrelated, since the null hypothesis could not be rejected in the data. ${ }^{7}$

\section{Results}

In this section we analyze the results. We compute the solutions of two different models where. In the first case we solve the model taking a log-linear approximation around the steady state and calibrate IST shocks along the lines of Raffo (2009) and TFP shocks as in Heathcote and Perri (2002). In the second case we solve the normalized model taking a log-linear approximation around the normalized steady state and then we will simulate the model using the parametrized law of motion of shocks as described in section III.. Since in the second case the shocks in the model are non-stationary, we need to rely on simulation techniques to obtain the relevant moments. As we show below, the implications of the two approaches with respect to the model's ability to solve the above-mentioned four puzzles are different. While Raffo's (2009) approach can easily account for them, while the alternative estimation approach cannot. The reason is that our estimated IST shocks are much less volatile than Raffo (2009) assumes.

\section{A. Model Parameterization}

We calibrate the model following Heathcote and Perri (2002) closely. The discount factor $\beta$ is set equal to 0.99 , which implies an annual rate of return on capital of 4 percent. We assume a cost of bond holdings, $\varsigma$, of 1 basis point (0.01). Parameters on technology are fairly standard in the literature. Thus, the capital share of output is set to $\alpha=0.36$, and home bias for home-country intermediate goods is set to $\omega=0.9$, which implies the observed import/output ratio in the steady state for the U.S. As in Raffo (2009), we assume a low value for the elasticity of substitution, $\theta=0.62$. This value is a bit higher than the lower bound used in Corsetti et al. (2008b). For model comparison, we also consider a relative higher value, $\theta=0.85$, as in Heathcote and Perri (2002).

We consider two different period utility functions. First, we analyze Cobb-Douglas

\footnotetext{
${ }^{7}$ Rabanal et al. (2010) use a model in which technology innovations are labor augmenting: $K\left(s^{t-1}\right)^{\alpha}\left(A\left(s^{t}\right) L\left(s^{t}\right)\right)^{1-\alpha}$. By definition, the standard deviation in this paper is thus equal to the ones reported in Rabanal et al (2010) multiplied by the constant $(1-\alpha)$.
} 
preferences as in Heathcote and Perri (2002):

$$
U\left[C\left(s^{t}\right), 1-L\left(s^{t}\right)\right]=\frac{\left\{C\left(s^{t}\right)^{\tau}\left[1-L\left(s^{t}\right)\right]^{1-\tau}\right\}^{1-\sigma}}{1-\sigma}
$$

When this is the case, we strictly follow Heathcote and Perri (2002) and fix the consumption share, $\tau$, at 0.34 , which also serves to pin down the steady-state value for the households' labor supply at 0.30 . The coefficient of risk aversion, $\sigma$, is set equal to 2. Backus et al. (1992) assume the same value for the latter parameter.

Second, we also consider the Greenwood, Hercowitz and Huffman (GHH) quasilinear preferences specification:

$$
U\left[C\left(s^{t}\right), 1-L\left(s^{t}\right)\right]=\frac{\left\{C\left(s^{t}\right)-\psi L\left(s^{t}\right)^{\nu}\right\}^{1-\sigma}}{1-\sigma} .
$$

Here we follow Raffo (2008) and fix $\nu$ and $\psi$, to 8.01 and 1163.4, so as to obtain the same steady-state value for the households' labor supply and the same labor supply elasticity as in the Cobb-Douglas specification. ${ }^{8}$ The value of $\sigma$ is set to be equal to the Cobb-Douglas case.

As it is standard in the IRBC literature, when we consider capital adjustment costs, we will calibrate $\phi$ so that in the model simulations, the relative standard deviation of investment with respect to output resembles the value in the U.S. data. The value of this parameter will change depending on the version of the model we are analyzing. We will describe the different values taken in the subsections.

Similarly, when we consider the capital utilization rate, we will normalize its steady-state value to 1 . The value of $b$ will be set to 0.0351 , since the first-order condition (11) relates $b$ to the steady-state value of the interest rate. The elasticity of marginal depreciation, $\varepsilon$, will be fixed at 1, in line with Baxter and Farr (2001), who rely on estimates provided by Basu and Kimball (1997). Finally, $\bar{\delta}$ will be set to 0.074 , such that $\delta(1)=0.025$.

\footnotetext{
${ }^{8}$ The labor supply elasticity for the Cobb-Douglas $\left(\varepsilon_{C D}\right)$ and GHH specifications $\left(\varepsilon_{G H H}\right)$ are defined as follows: $\varepsilon_{C D}=\frac{\left(1-L_{s s}\right)[1-\tau(1-\sigma)]}{\sigma L_{s s}}, \varepsilon_{G H H}=\frac{1}{\nu-1}$, where $L_{s s}$ is the steady-state value of $L\left(s^{t}\right)$.

Notice that if $\nu=\frac{1+\varepsilon_{C D}}{\varepsilon_{C D}}$, we effectively impose $\varepsilon_{C D}=\varepsilon_{G H H}$. Finally, $\psi$ is adjusted to obtain the desired $L_{s s}$, as implied by the steady-state conditions: $W_{s s}=(1-\alpha)\left(\frac{K_{s s}}{L_{s s}}\right)^{\alpha}=\psi \nu L_{s s}^{\nu-1}$, so that $\psi=\frac{W_{s s}}{\nu L_{s s}^{\nu-1}}$.
} 


\section{B. Solving the Puzzles}

We start by showing how the baseline IRBC framework exhibits the aforementioned puzzles. Then, we replicate Raffo's (2009) exercise: we add IST, endogenous capital utilization, and GHH utility. These three features (as long as we calibrate the IST shocks as in Raffo, 2009) will be sufficient to address the four puzzles discussed in the introduction. In order to stay close to Raffo's (2009) work, in this subsection we consider stationary shocks.

The baseline framework includes only stationary TFP shocks with Cobb-Douglas preferences, as in Heathcote and Perri (2002). In this case, neither IST shocks, investment adjustment costs, nor endogenous capital utilization is considered. Mimicking this paper, we assume the following stationary $\operatorname{VAR}(1)$ to characterize the stationary TFP process:

$$
\begin{gathered}
A\left(s^{t}\right)=\rho_{A} A\left(s^{t-1}\right)+\rho_{A}^{*} A^{*}\left(s^{t-1}\right)+\varepsilon^{A}\left(s^{t}\right), \\
A^{*}\left(s^{t}\right)=\rho_{A} A^{*}\left(s^{t-1}\right)+\rho_{A}^{*} A\left(s^{t-1}\right)+\varepsilon^{A, *}\left(s^{t}\right) .
\end{gathered}
$$

where $\rho_{A}=0.97, \rho_{A}^{*}=0.025, \operatorname{Var}\left(\varepsilon_{t}^{A}\right)=\operatorname{Var}\left(\varepsilon_{t}^{A, *}\right)=0.0073^{2}$, and $\operatorname{corr}\left(\varepsilon_{t}^{A}, \varepsilon_{t}^{A, *}\right)=0.29$. The first two rows of table 5(a), 5(b) and 5(c) show Hodrick-Prescott (HP) filtered moments from the data along those theoretical counterparts from the baseline IRBC model (M1).

We construct the RER as a geometric average of bilateral CPI-based RERs with respect to the Euro area, Japan, Canada, the United Kingdom and Australia. We use the same weights that the Federal Reserve uses to construct the real effective exchange rate of the U.S. dollar. Our sample period is 1973:4 to 2006:4. Real GDP, investment, consumption, and hours are constructed as described in the Appendix C. to build the TFP series.

When comparing both rows, the four "puzzles" that characterize this framework are evident. First, the baseline model tends to predict a relatively high cross-country consumption correlation, whereas the data indicate that consumption correlations tend to be lower than output correlations. Second, the standard model delivers a standard deviation of the terms of trade and the RER that is much lower than in the data. Backus et al. (1994) refer to these two anomalies as the "quantity" puzzle and "price" puzzle, respectively. The "international comovement" puzzle (Baxter, 1995) addresses the cross-country correlations of factor inputs. Investment and employment are positively correlated across countries, whereas the model delivers a negative correlation. Finally, the "Backus-Smith" puzzle refers to the fact that while models' strong risk-sharing conditions predict a positive (and very close to one) correlation between 
the RER and the ratio of consumption between countries, the data indicate that such a correlation is negative.

If TFP shocks are stationary, changes in permanent income following asymmetric shocks are small, implying little need for insurance markets. A single international asset allow households to obtain allocations similar to those when markets are complete. However, as discussed in Heathcote and Perri (2002), imposing a stationary technology process does not seem to constitute an important feature to judge the quantitative relevance of the model.

That is, in principle, near-unit-root TFP shocks with no spill overs to the other country can lead to significant changes in relative wealth (and thus relative consumption). In such a context, we could expect large differences between the behavior of the models with incomplete asset markets following the shock. However, the elasticity of substitution is an important additional determinant of the extent to which productivity shocks affect relative wealth. An increase in aggregate productivity in one country (due to a TFP shock) leads to an increase in the relative world supply of the good that country produces. This implies an increase in the terms of trade of the other country, since the good it produces becomes relatively scarcer. Standard trade elasticity values used within the IRBC framework imply that movements in the terms of trade almost exactly offset changes in relative productivity. The absence of sizable changes in relative wealth implies that a single risk-free bond is sufficient to closely replicate the complete markets allocation even when near-unit-root innovations are in place.

The inclusion of IST shocks breaks this logic. The terms of trade does not only reflect the relative scarcity of production, but also the relative demand for capital goods that this shock triggers. We first proceed by simply activating the stochastic process for the IST shock. Let us first assume a near unit-root process (though still stationary) with no spillovers across countries, i.e., $V\left(s^{t}\right)=\rho_{V} V\left(s^{t}\right)+\varepsilon^{V}\left(s^{t}\right), V^{*}\left(s^{t}\right)=\rho_{V} V^{*}\left(s^{t}\right)+\varepsilon^{V^{*}}\left(s^{t}\right)$, such that $\rho_{V}=0.999$. As Raffo (2009), we assume that the variance of the IST shock is about three times (3.6) as big as the one characterizing the TFP shocks, so that IST shocks explain most of the fluctuation in the model's endogenous variables. Mimicking Raffo (2009), we set the investment adjustment costs to match the relative standard deviation of investment with respect to output observed in the U.S. data ( $\phi$ at 0.595). ${ }^{9}$ We still do not consider endogenous capital utilization. Results are reported in the third row (M2) of the mentioned tables. This shock appears to be the "silver bullet" needed to successfully address the four puzzles in the literature.

The intuition for this result is provided in Figure 3 (refer to the thick solid line), which

\footnotetext{
${ }^{9}$ In fact, we choose $\phi$ so that the volatility of investment matches the data when $\rho_{V}=0.97$ (model M3 to be seen next) since this is the parametrization that is closest to Raffo (2009).
} 
plots the impulse response function to this IST shock (one standard deviation increase). As the IST shock hits the home-country, the domestic investment demand significantly increases. Given the aggregate resource constraint, home-country consumption decreases to accommodate the increase in investment demand.

The persistent IST shock leads to efficiency gains in the investment process which increases total productivity at home. That is, the investment boom increases the stock of capital available in the home economy. This more capital-intensive technology results in the increasing availability of home-country GDP, which becomes relatively abundant and further improves the terms of trade for the foreign economy. As a result the RER depreciates (i.e., RER increases). Foreign households feel richer because of the improvement in the terms of trade and unlike to their home-country neighbors consume more on impact (solving the "quantity" puzzles). In addition, cross-country relative consumption and the RER move in opposite directions (solving the "Backus-Smith" puzzle). Finally, foreign households take advantage of this sizable terms of trade effect and increase their labor supply and investment, magnifying over time their joint comovement with their home counterparts (solving the "international comovement" puzzle). On impact, however, this RER depreciation at home is significantly muted: due to home bias, the increase in the demand for the home intermediate good is relatively stronger as the shock hits (and slowly dissipates over time). Such fluctuations in the RER contribute to its increase volatility in the model simulations, which help us to better address the "price" puzzle.

If IST shocks are instead transitory $\left(\rho_{V}=0.97\right)$, as in Raffo (2009), the investment boom is relatively short-lived and the model fit worsen with respect to M2. The fourth row (M3) in the mentioned tables reflects this scenario. The thin solid line in Figure 3 graphs the corresponding impulse response. The "quantity" puzzle revives and the "Backus-Smith" puzzle worsens again.

Raffo (2009) partly solves this problem by adding endogenous capital utilization as in Greenwood et al. (1988). Refer to the fifth row (M4) in the mentioned tables and to the dashed line in Figure 3. Endogenous capital utilization serves as an effective endogenous propagation mechanism that helps to improve on the "Backus-Smith" puzzle dimension.

Nonetheless, this new mechanism generates other new counterfactuals and cannot solve the "quantity" puzzle. Given the resource constraint, a strong investment boom reduces consumption in the home economy so that the correlation between consumption and GDP turns out to be zero and much lower than in the data. Cleverly, Raffo (2009) addresses this problem using a GHH utility specification (M5), which suppresses the wealth effect responsible for dampening the response of the labor supply to positive productivity innovations. Absent this wealth effect in the labor supply, agents in both countries can increase the labor supply (and consumption) in response to shocks. This 
utility function also helps improving the "quantity" puzzle.

To conclude, in this section we have shown that the IST processes are able to improve the four mentioned puzzles if they are calibrated so as to explain most of the observed macroeconomic fluctuations. In this next subsection we will show that when we use the estimated VECM processes to simulate the model instead, the model can only partially address the puzzles.

Table 5a: Stationary Model Results

\begin{tabular}{lcccccc}
\hline \hline & $S D(G D P)$ & $S D(C)^{\mathrm{C}}$ & $S D(X)^{\mathrm{C}}$ & $S D(N)^{\bigcirc}$ & $S D(R E R)^{\bigcirc}$ & $\rho(R E R)$ \\
\hline Data & 1.58 & 0.76 & 4.55 & 0.75 & 3.06 & 0.82 \\
(M1) Baseline IRBC & 1.17 & 0.51 & 2.39 & 0.30 & 1.36 & 0.75 \\
(M2) M1 IST $\left(\rho_{V}=0.999\right)$ & 1.20 & 0.84 & 3.40 & 0.64 & 2.13 & 0.60 \\
(M3) M1 IST $\left(\rho_{V}=0.97\right)$ & 1.33 & 0.89 & 4.53 & 0.86 & 1.52 & 0.59 \\
(M4) M3 with Cap. Util. & 2.18 & 0.47 & 4.14 & 0.73 & 1.17 & 0.59 \\
(M5) GHH & 1.36 & 0.68 & 2.65 & 0.11 & 2.03 & 0.57 \\
\hline \hline
\end{tabular}

denotes relative to GDP.

Table 5b: Stationary Model Results

\begin{tabular}{lcccc}
\hline \hline & $C O R R(G D P, N)$ & $C O R R(G D P, C)$ & $C O R R(G D P, X)$ & $C O R R\left(R E R, \frac{C}{C^{*}}\right)$ \\
\hline Data & 0.87 & 0.84 & 0.91 & -0.04 \\
(M1) Baseline IRBC & 0.97 & 0.92 & 0.98 & 1.00 \\
(M2) M1 IST $\left(\rho_{V}=0.999\right)$ & 0.63 & 0.36 & 0.80 & -0.31 \\
(M3) M1 IST $\left(\rho_{V}=0.97\right)$ & 0.68 & 0.07 & 0.79 & 0.16 \\
(M4) M3 Cap. Util. & 0.89 & 0.00 & 0.93 & -0.12 \\
(M5) GHH & 0.97 & 0.65 & 0.87 & -0.21 \\
\hline \hline
\end{tabular}

Table 5c: Stationary Model Results

\begin{tabular}{lcccc}
\hline \hline & $C O R R\left(G D P, G D P^{*}\right)$ & $C O R R\left(C, C^{*}\right)$ & $C O R R\left(X, X^{*}\right)$ & $C O R R\left(N, N^{*}\right)$ \\
\hline Data & 0.44 & 0.36 & 0.28 & 0.40 \\
(M1) Baseline IRBC & 0.22 & 0.81 & -0.06 & -0.06 \\
(M2) M1 IST $\left(\rho_{V}=0.999\right)$ & 0.26 & 0.25 & 0.21 & 0.22 \\
(M3) M1 IST $\left(\rho_{V}=0.97\right)$ & 0.25 & 0.37 & 0.14 & 0.24 \\
(M4) M3 Cap. Util. & 0.34 & 0.47 & 0.20 & 0.32 \\
(M5) GHH & 0.41 & 0.67 & 0.18 & 0.69 \\
\hline \hline
\end{tabular}



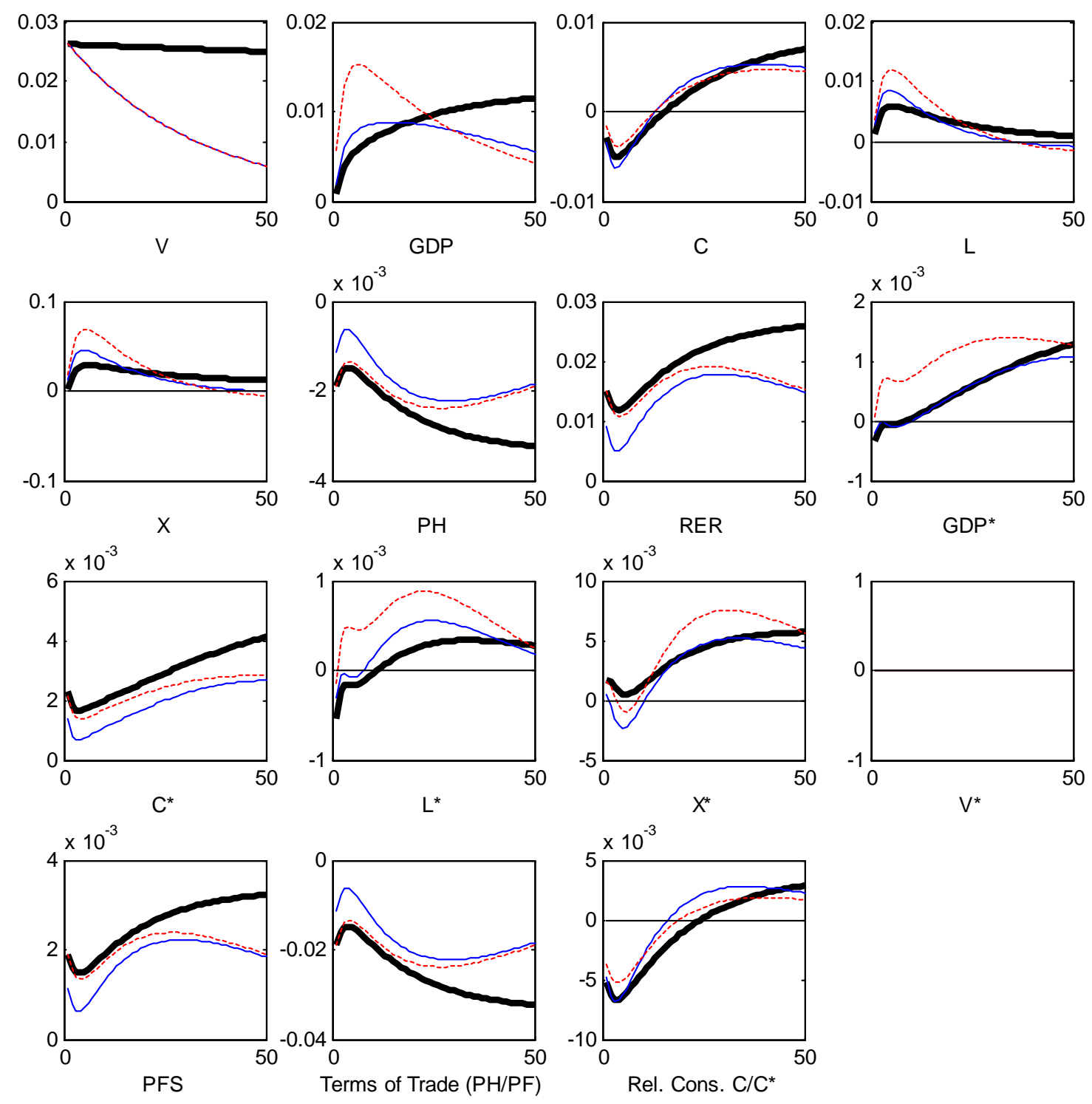

Figure 3: Impulse-Responses in the Stationary Model Note: Thick Solid: M2. Thin Solid: M3. Dashed: M4. 


\section{IRBC with the Estimated IST Shocks}

In this subsection we make to changes with respect to the last subsection. First, instead of calibrating the IST shocks, we simulate the model using the VECM estimates reported in section 3. Also, instead of using the stationary TFP shocks, as in Heathcote and Perri (2002), we use cointegrated TFP shocks as estimated in Rabanal et al. (2010). Hence, we consider the non-stationary version of the model where both TFP and IST shocks are cointegrated. We shall show that when that is the case, the fit of the model improves along some dimensions with respect to M1, but it is unable to fully solve the aforementioned puzzles. The reason behind the difference in the results is that while Raffo (2009) calibrates the variance of the IST processes to be almost three times the one characterizing the stationary TFP process, the estimated non-stationary IST shocks are much less volatile.

The first two rows in Tables 6(a), 6(b), and 6(c) depict the data and the moments obtained from a standard IRBC with Cobb-Douglas utility (M1NS) that includes only cointegrated TFP shocks as estimated in Rabanal et al. (2010). As discussed in that paper, the presence of unit root processes in TFP with slow convergence across countries leads to highly persistent differences in productivity across countries. As a result, the volatility of the RER increases and the model gets closer to the empirical evidence and the "price" puzzle improves with respect to the M1 model. Also, households in each country take advantage of either persistent productivity gains or sizable improvements in the terms of trade and jointly increase their labor supply and investment. This result is useful to address the "international comovement" puzzle with respect to the M1 model.

In the previous subsection, we showed that an arbitrary near-unit-root IST process with no spillovers across countries was the "silver bullet" needed to solve the four puzzles. Interestingly, our VECM estimates for the IST process imply similar dynamics: (a) IST processes for the U.S. and the R.W. are well-characterized by unit roots and (b) the estimated very low speed of convergence $\left(\kappa_{V}, \kappa_{V}^{*}\right)$ of these processes somewhat mimics the scenario with no spillovers in the stationary case. That is, despite the fact that the IST processes for both countries are cointegrated and co-move in the long run, these IST processes will converge very slowly when a shock hits one of the countries. Indeed, the shape of the impulse responses to a non-stationary shock (refer to the solid line in Figure 4) confirms this intuition, since the dynamics resemble those in Figure 3. However, as we are about to show, the quantitative results are less encouraging.

In the third row of Tables $6(\mathrm{a})-6(\mathrm{c})$, we consider a case with cointegrated IST and TFP 
shocks (M2NS). ${ }^{10}$ The "Backus-Smith" and the "quantity" puzzle, although slightly smaller, remain well in place. This is the by-product of consumption decline needed in home to accommodate higher investment expenditures with the presence of worsening terms of trade in the aftermath of IST shocks.

These results greatly depend on the elasticity of substitution of the final good $(\theta=0.62)$. For instance, the "Backus-Smith" puzzle is fully restored if we slightly increase the degree of substitutability between local and imported inputs $(\theta=0.85)$. This relatively high elasticity dampens the decline in the terms of trade in the home country and the corresponding increase in consumption and labor effort in the foreign economy in response to domestic shocks. Consequently, the RER volatility and the international comovement are also significantly reduced in such scenario. Refer to the fourth row (M2NSb) and thin-solid line in Figure 4. When we include capital utilization (fifth and sixth rows, M3NS and M3NSb), or GHH utility (seventh row, M4NS) specifications, results do not improve.

Why do our estimated IST processes generate such different results despite the fact that they lead to dynamics similar to the ones discussed in the stationary case? As mentioned above, in the previous subsection we followed Raffo (2009) and fixed the standard deviation of the IST shocks to be about three times as large as the one characterizing the TFP shock. Our estimates indicate that, in the data, the standard deviation of both technological processes is about of the same magnitude.

Would it be possible to recover Raffo's (2009) results if we increased the variance of the cointegrated IST shocks? The answer is yes. When non-stationary shocks are in place, we need to multiply the standard deviation of the IST shock by a factor of 7 , and set capital adjustment costs, $\phi$, equal to 6 , in order to properly address the puzzles. The last row (M5NS) of these tables depicts this case. This arbitrary calibration produces results closed to the ones obtained with M5.

\footnotetext{
${ }^{10}$ Note that in this case we do not consider investment adjusment costs. Since our estimated IST shocks have a smaller variance than the ones used by Raffo (2009) we do not need to include them to dampen the response of investment. Actually, zero adjustment costs will deliver a relative standard deviation of investment that is lower than the one observed in the data.
} 
Table 6a: Non-Stationary Model Results

\begin{tabular}{lcccccc}
\hline \hline & $S D(G D P)$ & $S D(C)^{\bigcirc}$ & $S D(X)^{\bigcirc}$ & $S D(N)^{\bigcirc}$ & $S D(R E R)^{\bigcirc}$ & $\rho(R E R)$ \\
\hline Data & 1.58 & 0.76 & 4.55 & 0.75 & 3.06 & 0.82 \\
(M1NS) Coint. TFP & 1.03 & 0.56 & 1.87 & 0.23 & 2.26 & 0.75 \\
(M2NS) M1NS IST & 1.09 & 0.62 & 2.40 & 0.38 & 2.12 & 0.73 \\
(M2NSb) M2NS $\theta=0.85$ & 1.07 & 0.62 & 2.63 & 0.40 & 1.05 & 0.75 \\
(M3NS) M2NS Cap. Util. & 1.37 & 0.52 & 2.58 & 0.43 & 1.73 & 0.73 \\
(M3NSb) M3NS $\theta=0.85$ & 1.36 & 0.57 & 2.72 & 0.44 & 0.90 & 0.72 \\
(M4NS) M3NS GHH & 0.88 & 0.72 & 2.25 & 0.16 & 2.15 & 0.75 \\
(M5NS) M3NS High SD & 1.69 & 0.73 & 4.04 & 0.80 & 2.48 & 0.68 \\
\hline \hline
\end{tabular}

denotes relative to GDP.

Table 6b: Non-Stationary Model Results

\begin{tabular}{lcccc}
\hline \hline & $C O R R(G D P, N)$ & $C O R R(G D P, C)$ & $C O R R(G D P, X)$ & $C O R R\left(R E R, \frac{C}{C^{*}}\right)$ \\
\hline Data & 0.87 & 0.84 & 0.91 & -0.04 \\
(M1NS) Coint. TFP & 0.98 & 0.96 & 0.99 & 0.99 \\
(M2NS) M1NS IST & 0.70 & 0.77 & 0.86 & 0.70 \\
(M2NSb) M2NS $\theta=0.85$ & 0.73 & 0.80 & 0.87 & 0.96 \\
(M3NS) M2NS Cap. Util. & 0.81 & 0.73 & 0.92 & 0.80 \\
(M3NSb) M3NS $\theta=0.85$ & 0.78 & 0.74 & 0.89 & 0.97 \\
(M4NS) M3NS GHH & -0.17 & 0.79 & 0.80 & 0.69 \\
(M5NS) M3NS High SD & 0.78 & 0.36 & 0.87 & -0.07 \\
\hline \hline
\end{tabular}

Table 6c: Non-Stationary Model Results

\begin{tabular}{lcccc}
\hline \hline & $C O R R\left(G D P, G D P^{*}\right)$ & $C O R R\left(C, C^{*}\right)$ & $C O R R\left(X, X^{*}\right)$ & $C O R R\left(N, N^{*}\right)$ \\
\hline Data & 0.44 & 0.36 & 0.28 & 0.40 \\
(M1NS) Coint. TFP & 0.00 & 0.77 & 0.25 & 0.30 \\
(M2NS) M1NS IST & 0.03 & 0.68 & 0.10 & 0.07 \\
(M2NSb) M2NS $\theta=0.85$ & -0.02 & 0.42 & -0.21 & -0.14 \\
(M3NS) M2NS Cap. Util. & 0.11 & 0.78 & 0.15 & 0.33 \\
(M3NSb) M3NS $\theta=0.85$ & 0.03 & 0.52 & -0.12 & 0.04 \\
(M4NS) M3NS GHH & 0.03 & 0.50 & -0.01 & -0.10 \\
(M5NS) M3NS High SD & 0.21 & 0.78 & 0.21 & 0.51 \\
\hline \hline
\end{tabular}

\section{Concluding Remarks}

Standard IRBC models with stationary TFP shocks fail to account for some important features of the data. In particular, there are four puzzles that are robust to different 

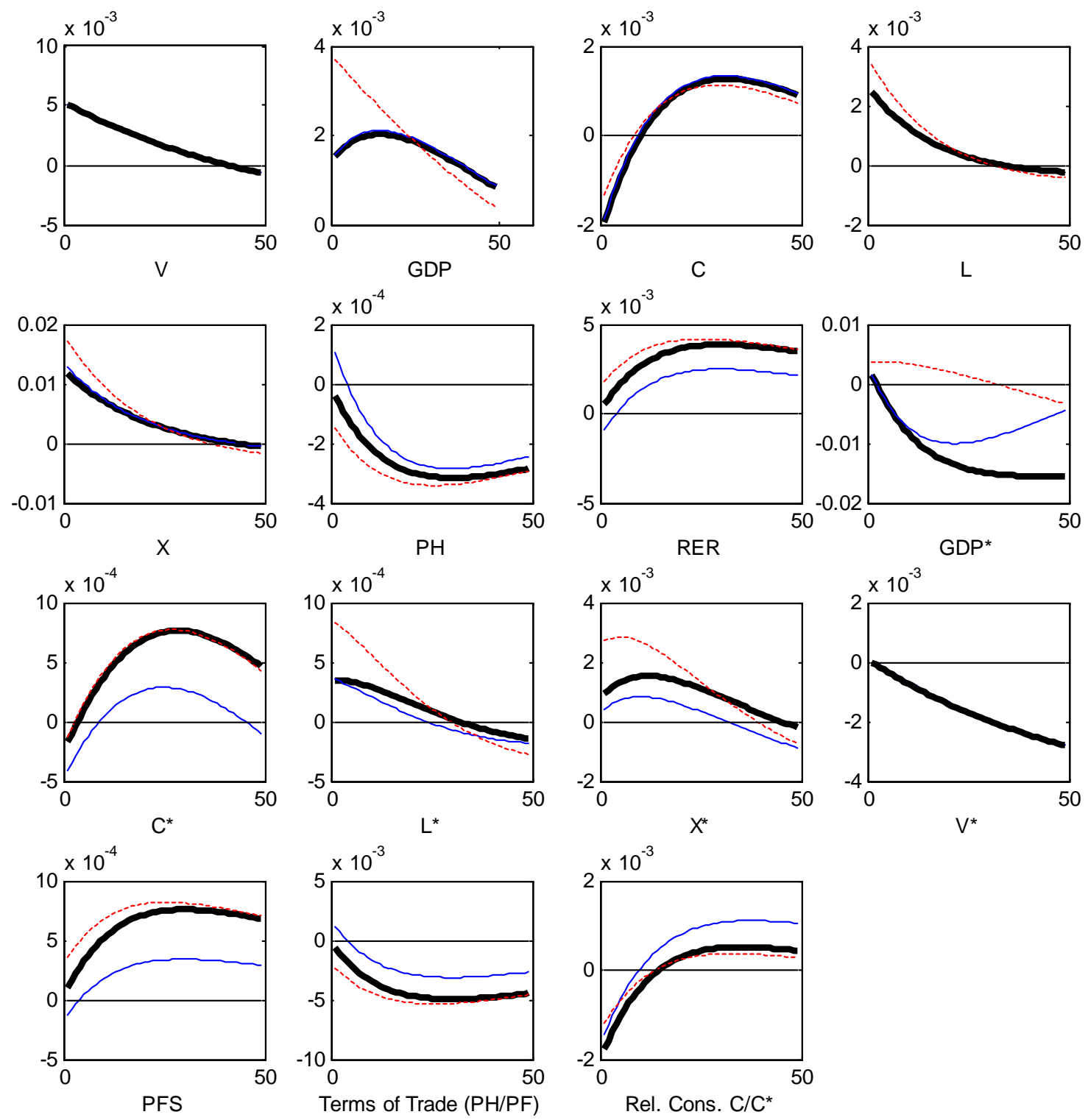

Figure 4: Impulse-Responses in the Non-Stationary Model.

Note: Thick Solid: M2NS Thin Solid: M2NSb Dashed: M3NS. 
model specifications and contradict the empirical evidence. First, risk sharing induces very strong positive cross-country consumption correlations, even when only incomplete markets are considered ("quantity" puzzle). Second, the RER is much more volatile in the data than in these models ("price" puzzle). Third, the equilibrium RER is closely related to the ratio of consumption across the two economies, opposite to the evidence ("Backus-Smith" puzzle). Finally, these models predict a counterfactual negative cross-country correlation of investment and employment "(international comovement" puzzle).

The literature has been trying to fill the gap between theory and data. One alternative to address the discrepancies between the model and the data consists of focusing on IST shocks. Raffo (2009) shows that thoughtfully parameterized IST shocks are sufficient to fill the gap.

However, the IST shocks also have a direct link to the data. In this paper, we use OECD data to characterize the IST shocks and estimate a VECM that characterizes their law of motion. Simulations of a model parameterized using these estimates do not support the results in Raffo (2009). The reason behind this discrepancy is that Raffo (2009) calibrates the standard deviations of his IST shocks to be around three times larger than its empirical equivalent as we estimate them (so that Raffo's (2009) IST shocks explain about two thirds of the variability of output). 


\section{References}

Altig, D., L. Christiano, M. Eichenbaum, and J. Lindé, 2005, "Firm-Specific Capital, Nominal Rigidities and the Business Cycle," NBER Working Paper No. 11034.

Backus, D., P. Kehoe and F. Kydland, 1992, "International Business Cycles," Journal of Political Economy, Vol. 100, pp. 745-75.

D. Backus, P. Kehoe and F. Kydland, 1994, "Relative Price Movements in Dynamic General Equilibrium Models of International Trade," in: R. van der Ploeg (Eds.) Handbook of International Macroeconomics, Wiley-Blackwell, pp. 62-96.

Basu, S. and M. Kimball, 1997, "Cyclical Productivity with Unobserved Input Variation," NBER Working Paper No. 5915.

Baxter, M., 1995, "International Trade and Business Cycles," NBER Working Paper No. 5025.

Baxter, M. and M. Crucini, 1995, "Business Cycles and the Asset Structure of Foreign Trade," International Economic Review, Vol. 36, pp. 821-54.

Baxter, M. and D. Farr, 2001, "Variable Factor Utilization and International Business Cycle," NBER Working Paper No. 8392.

Chari, V.V. , P. Kehoe and E. McGrattan, 2002, "Can Sticky Price Models Generate Volatile and Persistent Real Exchange Rates?," Review of Economic Studies, Vol. 69 , pp. 533-563.

Corsetti, G., L. Dedola and S. Leduc, 2008a, "International Risk Sharing and the Transmission of Productivity Shocks," Review of Economic Studies, Vol. 75, pp. 443-473.

Corsetti, G., L. Dedola and S. Leduc, 2008b, "High Exchange Rate Volatility and Low Pass-through," Journal of Monetary Economics, Vol. 55, pp. 1113-28.

Christoffel, K., K. Kuester, and T. Linzert, 2009, "The Role of Labor Markets for Euro Area Monetary Policy," European Economic Review, Vol. 53, pp. 908-36.

Engle R. and C. Granger, 1987, "Co-Integration and Error Correction:

Representation, Estimation, and Testing," Econometrica, Vol. 55, pp. 251-76.

Engel, C. and A. Matsumoto, 2009, "The International Diversification Puzzle When Goods Prices Are Sticky: It's Really about Exchange-Rate Hedging, Not Equity Portfolios," American Economic Journal: Macroeconomics, Vol. 1, pp. 155-88. 
Fisher, J., 2006, "The Dynamic Effects of Neutral and Investment-Specific Technology Shocks," Journal of Political Economy, Vol. 114, pp. 413-51.

García-Cicco J., R. Pancrazi, and M. Uribe "Real Business Cycles in Emerging Countries?," American Economic Review, forthcoming..

Greenwood, J., Z. Hercowitz, and G. Huffman, 1988, "The Role of Investment-Specific Technological Change in the Business Cycle," European Economic Review, Vol. 44, pp. 91-115.

Heathcote, J., and F. Perri, 2002, "Financial Autarky and International Business Cycles," Journal of Monetary Economics, Vol. 49, pp. 601-27.

Heathcote, J., and F. Perri, 2007, "The International Diversification Puzzle Is Not as Bad as You Think," NBER Working Paper No. 13483.

Ireland, P., 2009, "Stochastic Growth in the United States and the Euro Area," Boston College Working Papers in Economics No. 713.

Johansen, S., 1991, "Estimation and Hypothesis Testing of Cointegration Vectors in Gaussian Vector Autoregressive Models," Econometrica Vol. 59, pp. 1551-80.

Justiniano, A., G. Primicieri and A. Tambalotti, 2008, "Investment Shocks and Business Cycles," Federal Reserve Bank of New York Staff Report No. 322.

King, R., C., Plosser and S., Rebelo, 1988, "Production, Growth and the Business Cycle," Journal of Monetary Economics, Vol. 21, pp. 195-232.

MacKinnon, J., A. Haug and L. Michelis, 1999, "Numerical Distribution Functions of Likelihood Ratio Tests for Cointegration," Journal of Applied Econometrics, Vol. 14 (5), pp. 563-77.

Ng, S. and P. Perron, 2001, "LAG Length Selection and the Construction of Unit Root Tests with Good Size and Power," Econometrica Vol. 69, pp. 1519-54.

Rabanal, P., J. Rubio-Ramírez, and V. Tuesta, 2010, "Cointegrated TFP Processes and International Business Cycles," revised version of Federal Reserve Bank of Atlanta Working Paper 2009-23.

Raffo, A., 2008, "Net exports, Consumption Volatility and International Business Cycle Models," Journal of International Economics, Vol. 75, pp. 14-29.

Raffo, A., 2009, "Technology Shocks: Novel Implications for International Business Cycles", mimeo. 
Schmitt-Grohé, S and M. Uribe, 2008, "What's News in Business Cycles, " NBER Working Paper No. 14215.

Stockman, A., L. Tesar, 1995, "Tastes and Technology in a Two-Country Model of the Business Cycle: Explaining International Comovements," American Economic Review, Vol. 85, pp. 165-85. 


\section{Appendix I}

\section{A. Normalized Equilibrium Conditions}

In this Appendix we analyze the case of Cobb-Douglas utility function. For simplicity in the exposition, redefine $x\left(s^{t_{s}}\right)$ as $x_{t_{s}}$ and $\sum_{s^{t+1}} \pi\left(s^{t+1} / s^{t}\right)\{\}$ as $E_{t}\{\}$. Since the presence of two unit roots makes the model non-stationary, we rescale the variables by $\hat{Y}_{t}=\frac{Y_{t}}{Z_{t-1}}, \hat{C}_{t}=\frac{C_{t}}{Z_{t-1}}, \hat{X}_{t}=\frac{X_{t}}{Z_{t-1}}$, and $\hat{K}_{t-1}=\frac{K_{t-1}}{Z_{t-1} V_{t-1}}$ where $Z_{t}=A_{t}^{\frac{1}{1-\alpha}} V_{t}^{\frac{\alpha}{1-\alpha}}$. Similar normalizations will hold for the foreign-country.

Market clearing for the intermediate goods:

$$
\begin{aligned}
\hat{Y}_{H, t}+\hat{Y}_{H, t}^{*} & =\left(\frac{A_{t}}{A_{t-1}}\right)\left(\hat{K}_{t-1}^{d}\right)^{\alpha}\left(L_{t}\right)^{1-\alpha} \\
\hat{Y}_{F, t}+\hat{Y}_{F, t}^{*} & =\left(\frac{A_{t}^{*}}{A_{t-1}^{*}}\right)\left(\hat{K}_{t-1}^{*, d}\right)^{\alpha}\left(L_{t}^{*}\right)^{1-\alpha}
\end{aligned}
$$

Production function of the final good:

$$
\begin{gathered}
\hat{Y}_{t}=\left[\omega^{\frac{1}{\theta}} \hat{Y}_{H, t}^{\frac{\theta-1}{\theta}}+(1-\omega)^{\frac{1}{\theta}} \hat{Y}_{F, t}^{\frac{\theta-1}{\theta}}\left(\frac{Z_{t-1}^{*}}{Z_{t-1}}\right)^{\frac{\theta-1}{\theta}}\right]^{\frac{\theta}{\theta-1}} \\
\widehat{Y}_{t}^{*}=\left[\omega^{\frac{1}{\theta}} \widehat{Y}_{F, t}^{* \frac{\theta-1}{\theta}}+(1-\omega)^{\frac{1}{\theta}} \widehat{Y}_{H, t}^{*} \frac{\theta-1}{\theta}\left(\frac{Z_{t-1}}{Z_{t-1}^{*}}\right)^{\frac{\theta-1}{\theta}}\right]^{\frac{\theta}{\theta-1}}
\end{gathered}
$$

Market clearing final good:

$$
\begin{aligned}
\hat{Y}_{t} & =\hat{C}_{t}+\hat{X}_{t} \\
\hat{Y}_{t}^{*} & =\hat{C}_{t}^{*}+\hat{X}_{t}^{*}
\end{aligned}
$$

Labor supply:

$$
\begin{aligned}
& \frac{1-\gamma}{\gamma} \frac{\hat{C}_{t}}{\left(1-L_{t}\right)}=\hat{W}_{t} \\
& \frac{1-\gamma}{\gamma} \frac{\hat{C}_{t}^{*}}{\left(1-L_{t}^{*}\right)}=\hat{W}_{t}^{*}
\end{aligned}
$$


Marginal utility of consumption:

$$
\begin{aligned}
& \hat{\lambda}_{t}=\frac{\gamma}{\hat{C}_{t}}\left\{\hat{C}_{t}^{\gamma}\left(1-L_{t}\right)^{1-\gamma}\right\}^{1-\sigma} \\
& \hat{\lambda}_{t}^{*}=\frac{\gamma}{\hat{C}_{t}^{*}}\left\{\left(\hat{C}_{t}^{*}\right)^{\gamma}\left(1-L_{t}^{*}\right)^{1-\gamma}\right\}^{1-\sigma}
\end{aligned}
$$

where $\hat{\lambda}_{t}=\lambda_{t} Z_{t-1}^{1-\gamma(1-\sigma)}$ and $\hat{\lambda}_{t}^{*}=\lambda_{t}^{*} Z_{t-1}^{* 1-\gamma(1-\sigma)}$.

Risk-sharing

$E_{t}\left\{\frac{\hat{\lambda}_{t+1}^{*}}{\hat{\lambda}_{t}^{*}}\left[\left(\frac{Z_{t-1}^{*}}{Z_{t}^{*}}\right)^{1-\gamma(1-\sigma)}\right] \frac{\widetilde{P}_{H, t+1}}{\widetilde{P}_{H, t}} \frac{R E R_{t}}{R E R_{t+1}}\right\}=E_{t}\left\{\left[\frac{\hat{\lambda}_{t+1}}{\hat{\lambda}_{t}}\left(\frac{Z_{t-1}}{Z_{t}}\right)^{1-\gamma(1-\sigma)}\right] \frac{\widetilde{P}_{H, t+1}}{\widetilde{P}_{H, t}}\right\}-\frac{\phi}{\beta} \hat{D}_{t}$

where $\hat{D}_{t}=\left(\frac{D_{t}-D}{Z_{t-1}}\right)$.

The price of the bond

$$
\bar{Q}_{t}=\beta E_{t}\left\{\frac{\hat{\lambda}_{t+1}}{\hat{\lambda}_{t}}\left(\frac{Z_{t-1}}{Z_{t}}\right)^{1-\gamma(1-\sigma)} \frac{\widetilde{P}_{H, t+1}}{\widetilde{P}_{H, t}}\right\}-\phi \hat{D}_{t}
$$

Euler Equations:

$$
\begin{gathered}
\hat{\lambda}_{t}=\hat{\mu}_{t} \frac{V_{t}}{V_{t-1}}\left(1-\phi\left(\frac{\hat{X}_{t}}{\hat{X}_{t-1}} \frac{V_{t}}{V_{t-1}} \frac{Z_{t-1}}{Z_{t-2}}-\Lambda_{X}\right)\right)+ \\
\beta E_{t} \hat{\mu}_{t+1}\left(\frac{Z_{t}}{Z_{t-1}}\right)^{1-\gamma(1-\sigma)} \frac{V_{t+1}}{V_{t}}\left[\phi\left(\frac{\hat{X}_{t+1}}{\hat{X}_{t}} \frac{V_{t+1}}{V_{t}} \frac{Z_{t}}{Z_{t-1}}-\Lambda_{X}\right) \frac{\hat{X}_{t+1}}{\hat{X}_{t}} \frac{Z_{t}}{Z_{t-1}}-\frac{\phi}{2} \frac{V_{t}}{V_{t+1}}\left(\frac{\hat{X}_{t+1}}{\hat{X}_{t}} \frac{V_{t+1}}{V_{t}} \frac{Z_{t}}{Z_{t-1}}-\Lambda_{X}\right)\right. \\
\beta E_{t} \hat{\mu}_{t+1}^{*}\left(\frac{Z_{t}^{*}}{Z_{t-1}^{*}}\right)^{1-\gamma(1-\sigma)} \frac{V_{t+1}^{*}}{\hat{\lambda}_{t}^{*}}=\hat{\mu}_{t}^{*} \frac{V_{t}^{*}}{V_{t-1}^{*}}\left(1-\phi\left(\frac{\hat{X}_{t}^{*}}{\hat{X}_{t-1}^{*}} \frac{V_{t}^{*}}{V_{t-1}^{*}} \frac{Z_{t-1}^{*}}{Z_{t-2}^{*}}-\Lambda_{X}^{*}\right)\right)+ \\
\left.\hat{X}_{t}^{*} \frac{V_{t+1}^{*}}{V_{t}^{*}} \frac{Z_{t}^{*}}{Z_{t-1}^{*}}-\Lambda_{X}^{*}\right) \frac{\hat{X}_{t+1}^{*}}{\hat{X}_{t}^{*}} \frac{Z_{t}^{*}}{Z_{t-1}^{*}}-\frac{\phi}{2} \frac{V_{t}^{*}}{V_{t+1}^{*}}\left(\frac{\hat{X}_{t+1}^{*}}{\hat{X}_{t}^{*}} \frac{V_{t+1}^{*}}{V_{t}^{*}} \frac{Z_{t}^{*}}{Z_{t-1}^{*}}-\Lambda_{X}^{*}\right)
\end{gathered}
$$

where $\hat{\mu}_{t}=V_{t-1} Z_{t-1}^{1-\gamma(1-\sigma)} \mu_{t}$ and $\hat{\mu}_{t}^{*}=V_{t-1}^{*}\left(Z_{t-1}^{*}\right)^{1-\gamma(1-\sigma)} \mu_{t}^{*}$. 


$$
\begin{aligned}
\frac{V_{t}}{V_{t-1}}\left(\frac{Z_{t}}{Z_{t-1}}\right)^{1-\gamma(1-\sigma)} \hat{\mu}_{t} & =\beta E_{t}\left\{u_{t+1} \hat{R}_{t+1} \hat{\lambda}_{t+1}+\hat{\mu}_{t+1}\left(1-\delta\left(u_{t+1}\right)\right)\right\} \\
\frac{V_{t}^{*}}{V_{t-1}^{*}}\left(\frac{Z_{t}^{*}}{Z_{t-1}^{*}}\right)^{1-\gamma(1-\sigma)} \hat{\mu}_{t}^{*} & =\beta E_{t}\left\{u_{t+1}^{*} \hat{R}_{t+1}^{*} \hat{\lambda}_{t+1}^{*}+\hat{\mu}_{t+1}^{*}\left(1-\delta^{*}\left(u_{t+1}^{*}\right)\right)\right\}
\end{aligned}
$$

where $\hat{R}_{t}=R_{t} V_{t-1}$ and $\hat{R}_{t}^{*}=R_{t}^{*} V_{t-1}^{*}$

Capital Accumulation $\left(\hat{K}_{t-1}=\frac{K_{t-1}}{Z_{t-1} V_{t-1}}\right)$

$$
\begin{aligned}
\hat{K}_{t} \frac{Z_{t}}{Z_{t-1}} \frac{V_{t}}{V_{t-1}} & =\left(1-\delta\left(u_{t}\right)\right) \hat{K}_{t-1}+\frac{V_{t}}{V_{t-1}}\left(\hat{X}_{t}-\frac{\phi}{2} \frac{Z_{t-2}}{Z_{t-1}} \frac{V_{t-1}}{V_{t}} \hat{X}_{t-1}\left[\frac{\hat{X}_{t}}{\hat{X}_{t-1}} \frac{V_{t}}{V_{t-1}} \frac{Z_{t-1}}{Z_{t-2}}-\Lambda_{X}\right]^{2}(3 \AA)\right. \\
\hat{K}_{t}^{*} \frac{Z_{t}^{*}}{Z_{t-1}^{*}} \frac{V_{t}^{*}}{V_{t-1}^{*}} & =\left(1-\delta\left(u_{t}^{*}\right)\right) \hat{K}_{t-1}^{*}+\frac{V_{t}^{*}}{V_{t-1}^{*}}\left(\hat{X}_{t}^{*}-\frac{\phi}{2} \frac{Z_{t-2}^{*}}{Z_{t-1}^{*}} \frac{V_{t-1}^{*}}{V_{t}^{*}} X_{t-1}^{*}\left[\frac{\hat{X}_{t}^{*}}{\hat{X}_{t-1}^{*}} \frac{V_{t}^{*}}{V_{t-1}^{*}} \frac{Z_{t-1}^{*}}{Z_{t-2}^{*}}-\Lambda_{X}^{*}\right]^{2}\right)
\end{aligned}
$$

Real wages and rental rates of capital:

$$
\begin{aligned}
\alpha \hat{W}_{t} L_{t} & =(1-\alpha) \hat{K}_{t-1} \hat{R}_{t} \\
\alpha \hat{W}_{t}^{*} L_{t}^{*} & =(1-\alpha) \hat{K}_{t-1}^{*} \hat{R}_{t}^{*} \\
\hat{W}_{t} & =(1-\alpha) \widetilde{P}_{H, t}\left(\hat{K}_{t-1}^{d}\right)^{\alpha}\left(\frac{A_{t}}{A_{t-1}}\right) L_{t}^{-\alpha} \\
\hat{W}_{t}^{*} & =(1-\alpha) \widetilde{P}_{F, t}^{*}\left(\hat{K}_{t-1}^{d, *}\right)^{\alpha}\left(\frac{A_{t}^{*}}{A_{t-1}^{*}}\right)\left(L_{t}^{*}\right)^{-\alpha} \\
\hat{\lambda}_{t} \hat{R}_{t} & =b \hat{\mu}_{t} u_{t}^{\varepsilon} \\
\hat{\lambda}_{t}^{*} \hat{R}_{t}^{*} & =b \hat{\mu}_{t}^{*}\left(u_{t}^{*}\right)^{\varepsilon} \\
\delta_{t} & =\hat{\delta}+\frac{b}{1+\varepsilon} u_{t}^{1+\varepsilon} . \\
\delta_{t}^{*} & =\hat{\delta}+\frac{b}{1+\varepsilon}\left(u_{t}^{*}\right)^{1+\varepsilon} .
\end{aligned}
$$

Finally, let us give a look to the demand functions:

$$
\begin{gathered}
\hat{Y}_{H, t}=\omega\left(\widetilde{P}_{H, t}\right)^{-\theta} \hat{Y}_{t} \\
\hat{Y}_{F, t}=(1-\omega)\left(\widetilde{P}_{F, t}^{*} R E R_{t}\right)^{-\theta} \hat{Y}_{t} \frac{Z_{t-1}}{Z_{t-1}^{*}}
\end{gathered}
$$


Proceeding in a similar way, we get the demands for the foreign-country:

$$
\begin{aligned}
\widehat{Y}_{H, t}^{*} \frac{Z_{t-1}}{Z_{t-1}^{*}} & =(1-\omega)\left(\frac{\widetilde{P}_{H, t}}{R E R_{t}}\right)^{-\theta} \widehat{Y}_{t}^{*} \\
\widehat{Y}_{F, t}^{*} & =\omega\left(\widetilde{P}_{F, t}^{*}\right)^{-\theta} \widehat{Y}_{t}^{*}
\end{aligned}
$$

Auxiliary variable:

$$
n x_{t}=\frac{\widetilde{P}_{H, t} \hat{Y}_{H, t}^{*}-\widetilde{P}_{F, t}^{*} R E R_{t} \hat{Y}_{F, t}\left(\frac{Z_{t-1}^{*}}{Z_{t-1}}\right)}{\hat{Y}_{t}}
$$

The law of motion of the bond is:

$$
\widetilde{P}_{H, t} \bar{Q}_{t} \hat{D}_{t}=\widetilde{P}_{H, t} \hat{Y}_{H, t}^{*}-\widetilde{P}_{F, t}^{*} R E R_{t} \hat{Y}_{F, t}\left(\frac{Z_{t-1}^{*}}{Z_{t-1}}\right)+\tilde{P}_{H, t} \hat{D}_{t-1} \frac{Z_{t-2}}{Z_{t-1}}-\tilde{P}_{H, t} \frac{\phi}{2}\left(\hat{D}_{t}\right)^{2}
$$

Supplementary equation:

$$
\hat{K}_{t-1}^{d}=u_{t} \hat{K}_{t-1,} \quad \hat{K}_{t-1}^{d, *}=u_{t}^{*} \hat{K}_{t-1}^{*}
$$

\section{B. GHH Utility Specification}

We now analyze the GHH specification. The utility function is:

$$
\frac{\left\{C_{t}-\psi Z_{t-1} L_{t}^{\nu}\right\}^{1-\sigma}}{1-\sigma}
$$

where, as standard, we augment the $\mathrm{GHH}$ preferences by $Z_{t-1}$ to obtain a formulation that is consistent with balanced growth. The FOC's are respectively replaced as follows:

$$
\begin{gathered}
\psi Z_{t-1} \nu L_{t}^{\nu-1}=W_{t} \\
{\left[C_{t}-\psi Z_{t-1} L_{t}^{\nu}\right]^{-\sigma}=\lambda_{t}}
\end{gathered}
$$

Non-Stationary case Notice that for the non-stationary case, we have the following:

$$
\psi \nu L_{t}^{\nu-1}=\hat{W}_{t}
$$




$$
\left[\hat{C}_{t}-\psi L_{t}^{\nu}\right]^{-\sigma}=\hat{\lambda}_{t}
$$

Where $\hat{\lambda}_{t}=\lambda_{t} Z_{t-1}^{\sigma}$.

\section{Estimation of the VECMs for TFP Shocks}

\section{C.1 Data}

As mentioned, in order to estimate the VECM for the TFP process, Rabanal et al. (2010) use data for the U.S. and an aggregate for the R.W. For the U.S., they obtain quarterly real GDP data from the Bureau of Economic Analysis and hours and employment data from the Organization for Economic Cooperation and Development (OECD). Real capital stock data is also obtained from the OECD. The R.W. aggregate is the 15 countries of the Euro area, the United Kingdom, Canada, Japan, and Australia. This group accounts for about 50 percent of the basket of currencies that the Federal Reserve uses to construct the RER for the U.S. dollar. For the United Kingdom, Canada, Japan, and Australia they obtain nominal GDP, hours, employment, and real capital stock from the OECD. For the Euro area they take nominal GDP, employment, and real capital stock from AWM. Hours are as reported in Christoffel et al. (2009). ${ }^{11}$ The sample period goes from 1973:1 to 2006:4, which is when the hours series for the Euro area ends. Ideally, one would want to include additional countries that represent an important and increasing share of trade with the U.S., such as China and other emerging countries, but long quarterly series are not available.

They aggregate the nominal GDPs of the R.W. using PPP nominal exchange rates to convert each national nominal output to current U.S. dollars, and then use the output deflator of the U.S. (base year 2000) to convert the R.W. nominal output to constant U.S. dollars. Aggregate R.W. hours data are obtained by simply aggregating the number of employees times hours per employee for each country. Real capital stocks are aggregated (base year 2000) using the base year 2000 PPP RERs. The constructed (log) TFP processes are as follows:

$$
\log A\left(s^{t}\right)=\frac{\log Y\left(s^{t}\right)-(1-\alpha) \log L\left(s^{t}\right)-\alpha \log K\left(s^{t-1}\right)}{1-\alpha}
$$

\footnotetext{
${ }^{11}$ We are thankful to K. Christoffel and K. Kuester for providing us with the data.
} 
and

$$
\log A^{*}\left(s^{t}\right)=\frac{\log Y^{*}\left(s^{t}\right)-(1-\alpha) \log L^{*}\left(s^{t}\right)-\alpha \log K^{*}\left(s^{t-1}\right)}{1-\alpha}
$$

where $\alpha$ is the capital share of output and takes a value of 0.36 . Backus et al. (1992) and Heathcote and Perri $(2002,2007)$ use a similar approach when constructing (log) TFP series for the U.S. and a R.W. aggregate but ignoring capital dynamics. Given the focus on long-run properties, capital stock is added into the analysis.

\section{C.2 Integration and Cointegration Properties}

In this section, we follow Rabanal et al. (2010) and present evidence supporting the assumption that the (log) TFP processes for the U.S. and the R.W. are cointegrated of order $\mathrm{C}(1,1)$. First we show support the unit root assumption for the univariate processes. Second, the test for the presence of cointegrating relationships using the Johansen (1991) procedure. Both the trace and the maximum eigenvalue methods support the existence of a cointegrating vector.

Table A1: Unit Root tests

\begin{tabular}{lcccc}
\hline \hline & log TFP U.S. & \multicolumn{2}{c}{$\log$ TFP R.W. } \\
\hline Method & $\begin{array}{c}\text { statistic } \\
\text { sevel }\end{array}$ & $\begin{array}{c}\text { First Diff. } \\
\text { statistic }\end{array}$ & $\begin{array}{c}\text { Level } \\
\text { statistic }\end{array}$ & $\begin{array}{c}\text { First Diff. } \\
\text { statistic }\end{array}$ \\
\hline ADF & $-2.96^{+}$ & -11.57 & $-1.25^{+}$ & -9.35 \\
DF-GLS & $-1.94^{+}$ & -11.18 & $-0.21^{+}$ & -5.05 \\
$\mathrm{P}_{T}-$ GLS & $23.74^{+}$ & 1.61 & $123.18^{+}$ & 3.05 \\
$\mathrm{MZ}_{\alpha}$ & $-4.96^{+}$ & -84.20 & $-0.37^{+}$ & -14.70 \\
$\mathrm{MZ}_{t}$ & $-1.50^{+}$ & -6.48 & $-0.23^{+}$ & -2.48 \\
\hline $\mathrm{MSB}$ & $0.30^{+}$ & 0.07 & $0.63^{+}$ & $0.16^{\diamond}$ \\
\hline \hline
\end{tabular}

\footnotetext{
Notes: ADF stands for augmented Dickey-Fuller test. DF-GLS stands for Elliott-Rothenberg-Stock detrended residuals test statistic. PT-GLS stands for Elliott-Rothenberg-Stock Point-Optimal test statistic.

$\mathrm{MZ}_{\alpha}, \mathrm{MZ}_{t}$, and MSB stand for the class of modified tests analyzed in Ng-Perron (2001).

For ADF and DF-GLS we present t-Statistics, for P T-GLS we present P-Statistics and for the $\mathrm{MZ}_{\alpha}, \mathrm{MZ}_{t}$, and MSB we present the $\mathrm{Ng}$-Perron test statistics.

+ denotes Null Hypothesis of unit root not rejected at 5 percent level.

$\diamond$ denotes Null Hypothesis of unit root not rejected at 5 percent level but rejected at 10 percent.
}

Univariate analysis of the (log) TFP processes for the U.S. and the R.W. strongly indicates that both series can be characterized by unit root processes with drift. Table A1 presents results for the U.S. (log) TFP process using the following commonly applied unit root tests: augmented Dickey-Fuller; the DF-GLS and the optimal point statistic $\left(P_{T} G L S\right)$, both of Elliott et al. (1996); and the modified $\mathrm{MZ}_{\alpha}, \mathrm{MZ}_{t}$, and MSB of Ng and Perron (2001). The lag length is chosen using the Schwartz information 
criteria. In each case a constant and a trend are included in the specification. Table A1 also presents the same unit root test results for the R.W. (log) TFP process. None of the test statistics are even close to rejecting the null hypothesis of unit root at the 5 percent critical value. Using the same statistics, unit root tests on the first difference of the (log) TFP processes for the U.S. and the R.W. are stationary. For the U.S. all the tests reject the null hypothesis of unit root at the 5 percent critical value. For the R.W. all the tests reject the null hypothesis of unit root at the 5 percent critical value except MSB tests that rejects it at the 10 percent value.

Table A2: Cointegration Statistics II: Johansen's test

\begin{tabular}{lccccc}
\hline \hline Number of Vectors & Eigenvalue & Trace & p-value & Max-Eigenvalue & p-value \\
\hline 0 & 0.14 & 24.93 & 0.001 & 21.52 & 0.003 \\
1 & 0.02 & 3.86 & 0.07 & 3.84 & 0.07 \\
\hline \hline
\end{tabular}

Note: p-values as reported in MacKinnon-Haug-Michelis (1999).

Once we have presented evidence that strongly indicates that the (log) TFP for the U.S. and the R.W. is well characterized by integrated processes of order one, we now focus on presenting evidence supporting our assumption that the processes are cointegrated. If $\log A\left(s^{t}\right)$ and $\log A^{*}\left(s^{t}\right)$ share one common stochastic trend (balanced growth), an estimated VAR has to have a single eigenvalue equal to one and all other eigenvalues have to be less than one. To check this possibility Rabanal et al. (2010) estimate an unrestricted VAR with one lag and a deterministic trend for the two-variables system $\left[\log A\left(s^{t}\right), \log A^{*}\left(s^{t}\right)\right]$ where the number of lags was chosen using the Schwarz information criterion. The results are as expected: the highest eigenvalue equals one, while the second highest is 0.95 . But this is not a formal test of cointegration. Table A2 reports results from the unrestricted cointegration rank test using the trace and the maximum eigenvalue methods as defined by Johansen (1991). The cointegration tests assumes linear trend and a constant in the cointegrating vector. Clearly, the data strongly support a single eigenvalue.

\section{C.3 The VECM Model}

In the last subsection, we presented evidence that $\log A\left(s^{t}\right)$ and $\log A^{*}\left(s^{t}\right)$ are cointegrated of order $\mathrm{C}(1,1)$. In this subsection we provide some additional results. First, we show that the null hypothesis of $\gamma=1$ cannot be rejected by the data using a likelihood ratio test. This is very important because a cointegrating vector $(1,-1)$ implies that the balanced growth path hypothesis cannot be rejected. Second, we also use the likelihood ratio test to present evidence supporting the null hypothesis that the 
coefficients related to the speed of adjustment in the cointegrating vector are equal and of opposite sign, i.e., $\kappa=-\kappa^{*}$. In Table A3, we present the outcome of the two likelihood ratio tests. Note that the tests are incremental.

Table A3: Likelihood ratio tests

\begin{tabular}{lccc}
\hline \hline Restriction & Likelihood value & Degrees of freedom & p-value \\
\hline None & 992.88 & - & - \\
$\gamma=1$ & 992.88 & 1 & 0.96 \\
$\kappa=-\kappa^{*}$ & 992.3 & 2 & 0.57 \\
\hline \hline
\end{tabular}

